\title{
An Experimental Investigation of the Hydrodynamic and Heat-Transfer Behavior of Aqueous Foam in Laminar Tube Flow
}

\author{
SAND- $-85-1922$ \\ B. F. Blackwell \\ DE88 004954 \\ Aerothermodynamics Division \\ Keri Butler Sobolik \\ Thermal Test and Analysis Division \\ Sandia National Laboratories \\ Albuquerque, NM 87185
}

\begin{abstract}
The structure of both static and dynamic aqueous foam samples has been observed photographically. Velocity profiles for a pipe-flow configuration were measured using a hot-film anemometer and an indirect calibration method. Temperature profiles at the end of a 3-m-long test section were measured using a thermocouple probe on a traversing mechanism. A finite-control-volume model of the energy equation for the flowing foam and the surrounding pipe was developed and compared with experimental results.
\end{abstract}

\section{DISCLAIMER}

This report was prepared as an account of work sponsored by an agency of the United States Government. Neither the United States Government nor any agency thereof, nor any of their employees, makes any warranty, express or implied, or assumes any legal liability or responsibility for the accuracy, completeness, or usefulness of any information, apparatus, product, or process disclosed, or represents that its use would not infringe privately owned rights. Reference herein to any specific commercial product, process, or service by trade name, trademark, manufacturer, or otherwise does not necessarily constitute or imply its endorsement, recommendation, or favoring by the United States Government or any agency thereof. The views and opinions of authors expressed herein do not necessarily state or teflect those of the United States Government or any agency thereof. 


\section{DISCLAIMER}

This report was prepared as an account of work sponsored by an agency of the United States Government. Neither the United States Government nor any agency Thereof, nor any of their employees, makes any warranty, express or implied, or assumes any legal liability or responsibility for the accuracy, completeness, or usefulness of any information, apparatus, product, or process disclosed, or represents that its use would not infringe privately owned rights. Reference herein to any specific commercial product, process, or service by trade name, trademark, manufacturer, or otherwise does not necessarily constitute or imply its endorsement, recommendation, or favoring by the United States Government or any agency thereof. The views and opinions of authors expressed herein do not necessarily state or reflect those of the United States Government or any agency thereof. 


\section{DISCLAIMER}

Portions of this document may be illegible in electronic image products. Images are produced from the best available original document. 


\section{Contents}

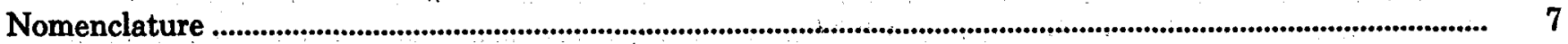

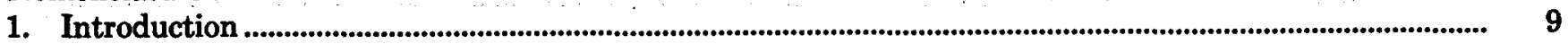

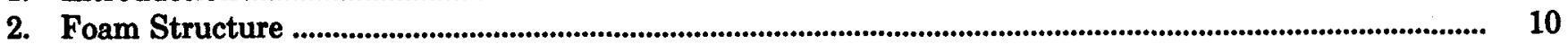

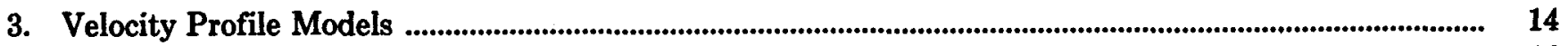

4. Predictions of Temperature Profiles and Heat Transfer ........................................................................ 16

5. Analysis of the Experimental Velocity and Temperature Data ........................................................................ 21

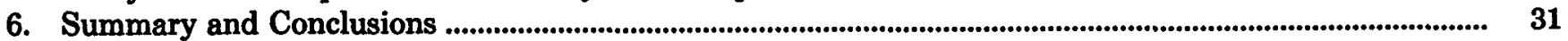

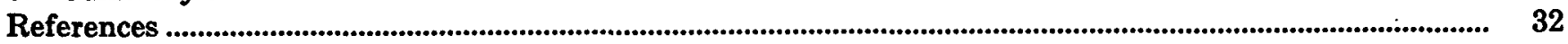

APPENDIX A -Description of the Experimental Apparatus .......................................................................... 33

APPENDIX B-Development of Finite-Control-Volume Model for Experimental Test Section ................... 37

APPENDIX C-Description of Temperature-Profile Probe ...................................................................................... 43

APPENDIX D-Calibration of Hot-Film Anemometer .....................................................................................4

\section{Figures}

1 Schematic of Wellbore Cross-Section

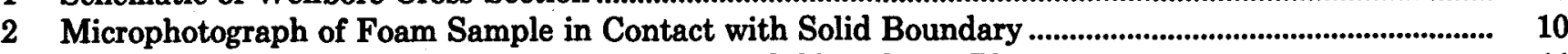

3 Schematic of Intersection Between Foam Cell and Glass Cover Plate ......................................................... 11

4 Microphotograph of Foam Sample Focused on Third Foam Layer Down ................................................ 11

5 Photograph (15X) of Foam Sample $(\phi=0.2)$ Brought to Rest While Maintaining Test-Section Pressure .................................................................................................................................. 12

6 Photograph (15X) of Flowing $(0.64 \mathrm{ft} / \mathrm{s})$ Foam Sample $(\phi=0.2)$.

Dimensionless Velocity Profile for Bingham Plastic $(m=1)$ with $\mathrm{c}=0.0$ to $0.8 \ldots \ldots \ldots \ldots . . . . . . . . . . . . . . . . . . . . . .114$

8 Dimensionless Velocity Profile for Bulkley-Herschel Fluid $(m=2.0)$ for $c=0.0$ to $0.8 \ldots \ldots \ldots . . . . . . . . . . . . .15$

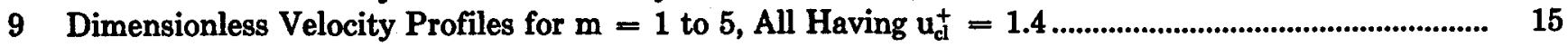

10 Temperature Profile Predictions at the End of a 3-m Isothermal-Wall Test Section and

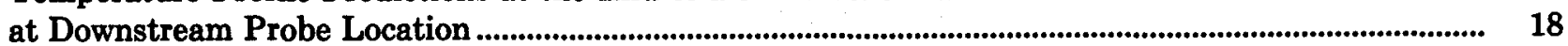

11 Schematic of Finite-Control-Volume Model for Conjugate Heat-Transfer Problem ................................ 19

12 Numerical Predictions of Test-Section Inner and Outer Wall Temperatures, Average Foam Temperatures, and Bulk Foam Temperatures ................................................................................ 19

13 Predicted Temperature Profile at End of Heated Section and Probe Location, Run 30A ..................... 20

14 Hot-Film-Probe Output Voltage as a Function of Position for a Nominal Liquid Volume Fraction of 0.2 and Various Flow Rates.................................................................................................. 21

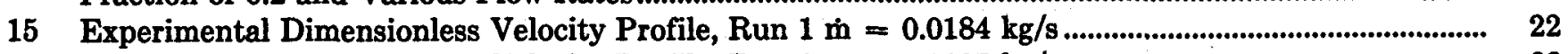

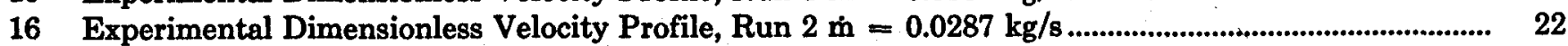

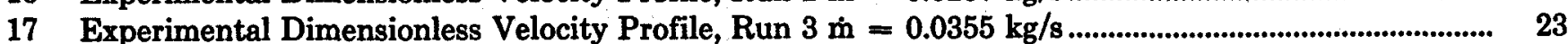

18 Experimental Dimensionless Velocity Profile, Run $4 \mathrm{~m}=0.0614 \mathrm{~kg} / \mathrm{s}$................................................... 23

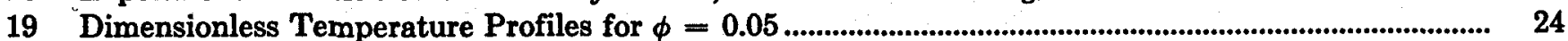

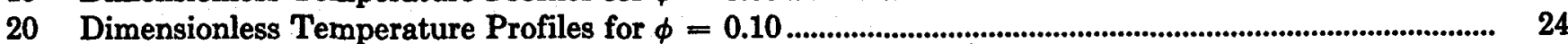

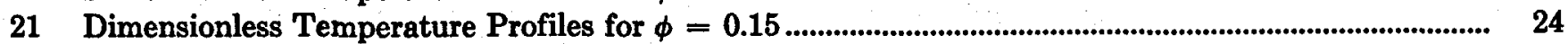

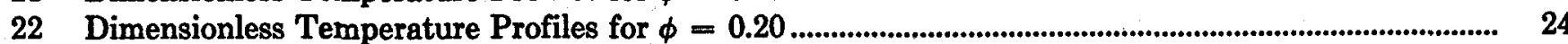

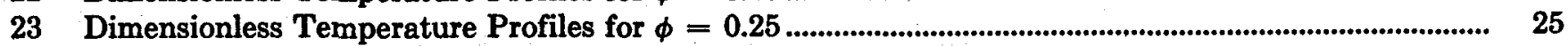

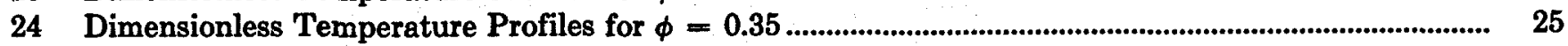

25 Dependence of Thermal-Boundary-Layer Thickness on Peclet Number ..................................................... 26

26 Dependence of Average Nusselt Number on Peclet Number ........................................................................ 26

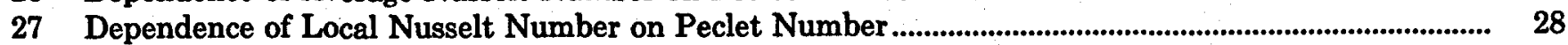

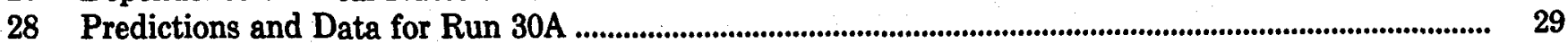

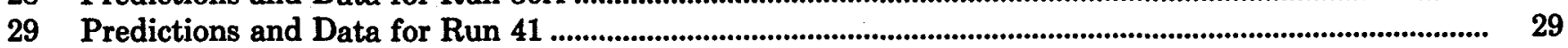

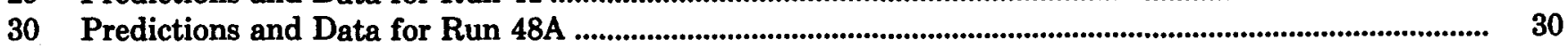




\section{Tables}

1 Dimensionless Velocity Gradient and the Function $\mathbf{g}(\mathbf{c}, \mathrm{m})$ as Functions of $\mathrm{c}$ for Several

Values of the Power-Law Exponent m.

2 Transient Simulation for Run 30A

20

3 Experimental Condition for Velocity-Profile Measurements .................................................................. 22 


\section{Nomenclature}

\section{Terms}

\begin{tabular}{|c|c|}
\hline A & Surface area of the test section \\
\hline$A_{c}$ & Cross-sectional area of the test section \\
\hline c & Yield-stress to wall-shear-stress ratio $=\tau_{\mathrm{y}} / \tau_{\mathrm{w}}$ \\
\hline C & Ratio of cold-to-hot fluid capacity rates \\
\hline$C_{p}$ & Specific heat at constant pressure \\
\hline D & Test section diameter \\
\hline $\mathbf{E}$ & Anemometer Voltage \\
\hline g & See Equation (4-4) \\
\hline$\underline{\mathbf{h}}_{\mathbf{z}}$ & Local heat-transfer coefficient \\
\hline & Average heat-transfer coefficient \\
\hline $\mathbf{k}, \mathbf{k}_{\ell}, \mathbf{k}_{\mathbf{z}}$ & Thermal conductivity of foam, liquid, and gaseous constituents, respectively \\
\hline & Distance between pressure-measurement ports \\
\hline m & Exponent $=1 / \mathrm{n}$ \\
\hline$\dot{\mathbf{m}}$ & Mass flow rate \\
\hline $\mathbf{n}$ & Exponent, Equation (3-1) \\
\hline $\mathrm{Nu}_{\mathrm{x}}$ & Local Nusselt number based on bulk temperature, Equation (5-1) \\
\hline$\tilde{N u}_{\mathbf{x}}$ & Local Nusselt number based on inlet temperature, Equation (5-2) \\
\hline$\overline{\mathbf{N}} \mathbf{u}$ & Average Nusselt number $=\frac{h_{x} D}{k}$ \\
\hline NTU & Number of transfer units, $U A /\left(\dot{m} C_{p}\right)$ \\
\hline $\mathbf{p}$ & Pressure \\
\hline $\mathbf{P e}$ & Peclet number $=\mathrm{\pi D} / \alpha$ \\
\hline$\dot{\mathbf{q}}$ & Heat flux \\
\hline $\mathbf{r}$ & Radial position \\
\hline $\mathbf{r}_{\mathbf{w}}$ & Wall or tube radius \\
\hline $\mathbf{r}^{+}$ & Dimensionless radial position $=r / r_{w}$ \\
\hline $\operatorname{Re}$ & Reynolds number $=\rho \overline{\mathrm{dD}} / \eta$ \\
\hline $\mathbf{T}$ & Temperature \\
\hline $\mathbf{T}_{\mathbf{b}}$ & Bulk foam temperature $=\frac{2}{r_{w}^{2} \bar{u}} \int_{0}^{r_{w}} u T r d r$ \\
\hline $\begin{array}{l}\mathbf{T}_{\mathbf{i}} \\
\mathbf{T}_{\mathbf{w}}\end{array}$ & $\begin{array}{l}\text { Temperature of foam at the inlet to the test section } \\
\text { Test-section wall temperature }\end{array}$ \\
\hline $\mathbf{T}$ & Average foam temperature $=\frac{2}{r_{w}^{2}} \int_{0}^{r_{w}} \operatorname{Trdr}$ \\
\hline $\mathbf{u}$ & Local velocity \\
\hline $\mathbf{u}$ & Average velocity $=\frac{2}{r_{w}^{2}} \int_{0}^{r_{w}}$ urdr \\
\hline $\mathbf{u}_{\mathrm{CL}}$ & Centerline velocity \\
\hline $\mathbf{u}^{+}$ & Dimensionless local velocity $=u / \bar{u}$ \\
\hline $\mathbf{u}^{\prime \prime \prime}$ & Viscous dissipation \\
\hline $\mathrm{U}$ & Overall heat-transfer coefficient \\
\hline $\boldsymbol{v}$ & Volume \\
\hline $\mathbf{x}$ & Axial position \\
\hline$x^{+}$ & Dimensionless axial position $=\left(\mathrm{x} / \mathrm{r}_{\mathrm{w}}\right) / \mathrm{Pe}$ \\
\hline$\alpha$ & Thermal diffusivity of foam \\
\hline & Gamma function \\
\hline
\end{tabular}




\section{Nomenclature (continued)}

$\delta$

$\Delta \mathbf{p}_{\mathrm{f}}$

$\epsilon$

$\eta$

$\theta$

$\tilde{\theta}$

$\rho, \rho_{\ell}, \rho_{\mathrm{g}}$

$\boldsymbol{T}$

$\tau_{\mathrm{w}}$

$\tau_{\mathbf{y}}$

$\phi$

Thermal-boundary-layer thickness

Pressure change due to friction

Heat exchanger effectiveness

Viscosity

Dimensionless temperature, $\left(T_{w}-T\right) /\left(T_{w}-T_{i}\right)$

Dimensionless temperature, $\left(T_{h}-T\right) /\left(T_{h}-T_{i}\right)$

Density of foam, liquid, and gas constituents, respectively

Local shear stress

Wall shear stress

Yield stress

Liquid volume fraction

\section{Subscripts}

$\mathrm{amb}$

b

c

h

hw

i

o

Ambient

Bulk

Cold fluid

Hot fluid

Hot water

Inlet

Outlet

Inner surface of the test-section wall

Outer surface of the test-section wall 


\section{An Experimental Investigation of the Hydrodynamic and Heat-Transfer Behavior of Aqueous Foam in Laminar Tube Flow}

\section{Introduction}

Aqueous foams have been used for a number of years as petroleum drilling fluids. Some of the reported advantages of aqueous foams include

- Low density produces low bottom-hole pressure

- Sand and cuttings fall back very little when circulation stops

- Low loss of circulation into surrounding formation.

It has been proposed that these same advantages would also apply to geothermal drilling where the formation temperature can approach $250^{\circ} \mathrm{C}\left(482^{\circ} \mathrm{F}\right)$. Before one can determine if foams will function in a geothermal environment, it is desirable to be able to predict foam temperatures as a function of position and time. Figure 1 presents a schematic cross-section of a typical wellbore. Foam is injected at the surface and flows down the center pipe. After passing through the drill bit, the foam/cuttings mixture flows up the annulus. Because of its large viscosity, foam is very efficient in the removal of cuttings. Heat is transferred from the hot formation through the casing wall to the upward flowing foam in the annulus. The foam in the annulus in turn heats the foam flowing down the drill pipe. The flow arrangement is very similar to a counter flow or bayonet-type heat exchanger. The foam temperature will depend on distance below the surface, position within the center pipe or annulus space, and time. To predict foam operating temperatures, it is necessary to know the convective heattransfer rate between the foam and the pipe surfaces it contacts. The purpose of this study was to provide experimental data on the thermal behavior of aqueous foams flowing in a tube-flow geometry that could be used to verify analytical/numerical prediction schemes. These prediction schemes could then be used to perform system studies to determine optimum liquid volume fraction at the injection point, effect of the high temperature on lifting capacity, and fluid handling requirements.

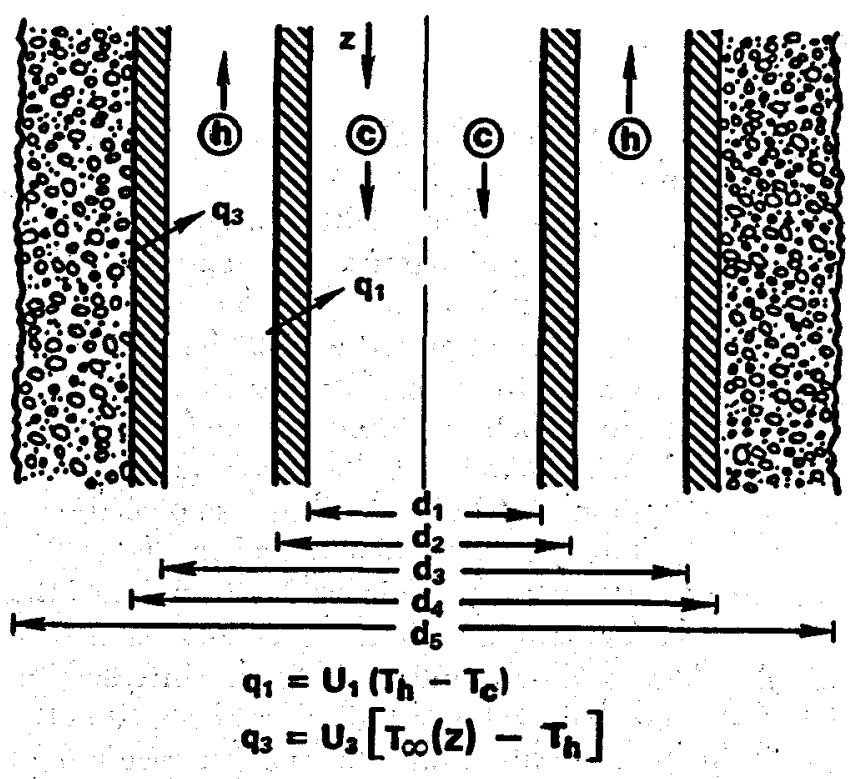

Figure 1. Schematic of Wellbore Cross-Section 


\section{Foam Structure}

Aqueous foams consist of a liquid and a gas phase: the liquid phase is usually water with approximately $1 \%$ surfactant added to reduce the surface tension; the gas phase is typically air or nitrogen, with nitrogen being used in corrosive environments. In the liquid volume fraction range of interest $(0.05$ to 0.35$)$ Bikerman $^{1}$ describes foams as gas bubbles separated by thin liquid films, as opposed to gas emulsions in which the thickness of the interstitial liquid layers is approximately the same as the diameter of the bubble.

The term liquid volume fraction is used to define the relative amounts of liquid and gas present in a foam:

$\phi=\frac{\text { liquid volume }}{\text { liquid volume }+ \text { gas volume }}$.

The foam density is related to the liquid volume fraction by

$\rho=\phi \rho_{\ell}+(1-\phi) \rho_{\mathrm{g}}$

where $\rho, \rho_{l}$, and $\rho_{g}$ are the densities of foam, liquid, and gas components, respectively.

Figure 2 is a microphotograph of a representative foam sample. This photograph was taken of foam generated at a liquid volume fraction of approximately 0.2 at a nominal pressure of 2.2 bar (32 psia), and then expanded to atmospheric pressure $(0.8 \mathrm{bar}$, $12.2 \mathrm{psia}$ ) during which the liquid volume fraction was reduced to approximately 0.1 . The foam was captured in a glass container and a glass cover was placed over the sample. The horizontal black band in Figure 2 is the vertical wall of the container. The purpose of the photograph was twofold: first, the cellular structure of the foam is shown and second, the intersection between foam and a solid boundary is shown. Note the presence of a small bubble at the intersection of several cell boundaries. The cell boundary is defined by the two dark parallel lines. Note also the presence of two faint lines parallel to the cell boundary; these lines define the meniscus where the cell wall comes in contact with the glass cover plate; a schematic of this intersection is shown in Figure 3. The photograph in
Figure 2 suggests that the presence of a solid boundary alters the structure of the foam; hence, the heat and momentum transfer mechanism near the boundary may be different from that at distances greater than several cell diameters from the wall. The liquid volume fraction of this foam sample is not known because the photograph was taken approximately $9.5 \mathrm{~min}$ after the sample was initially drawn; the liquid volume fraction continues to decrease with time because of evaporation and gravity drainage of the liquid component.

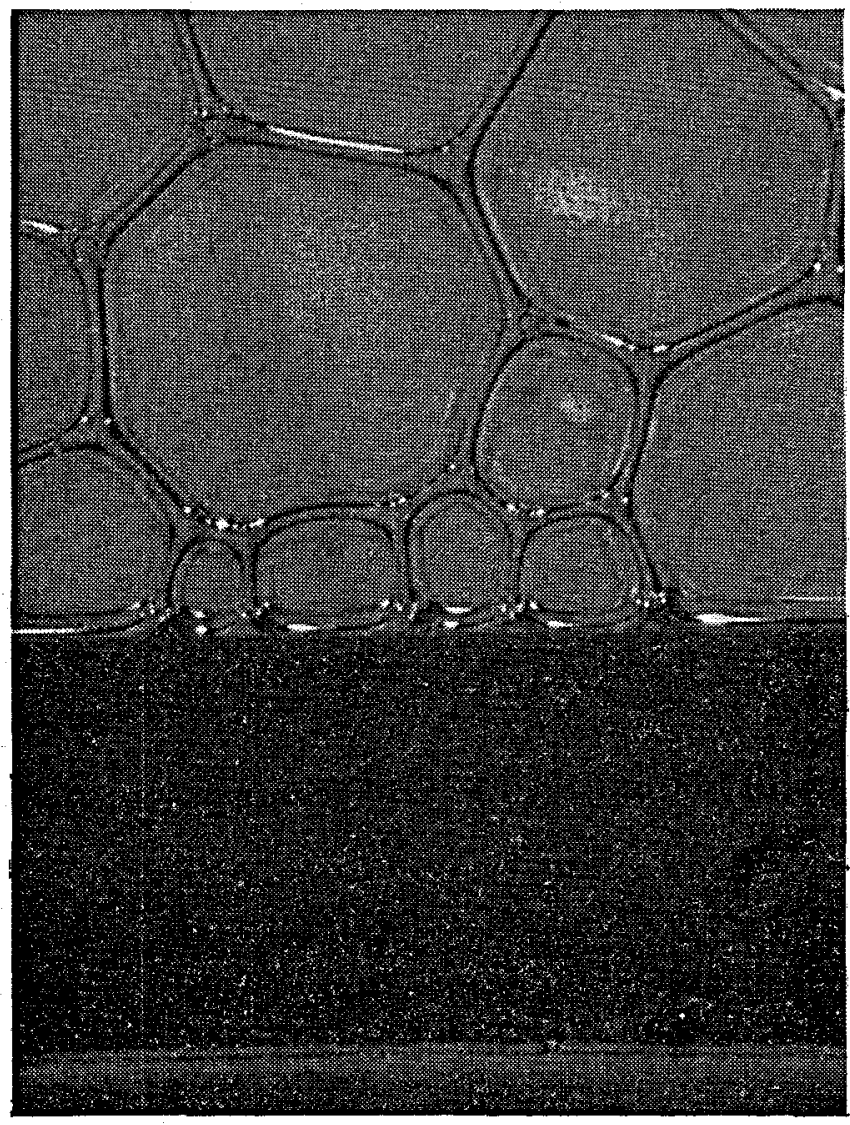

Figure 2. Microphotograph of Foam Sample in Contact with Solid Boundary 

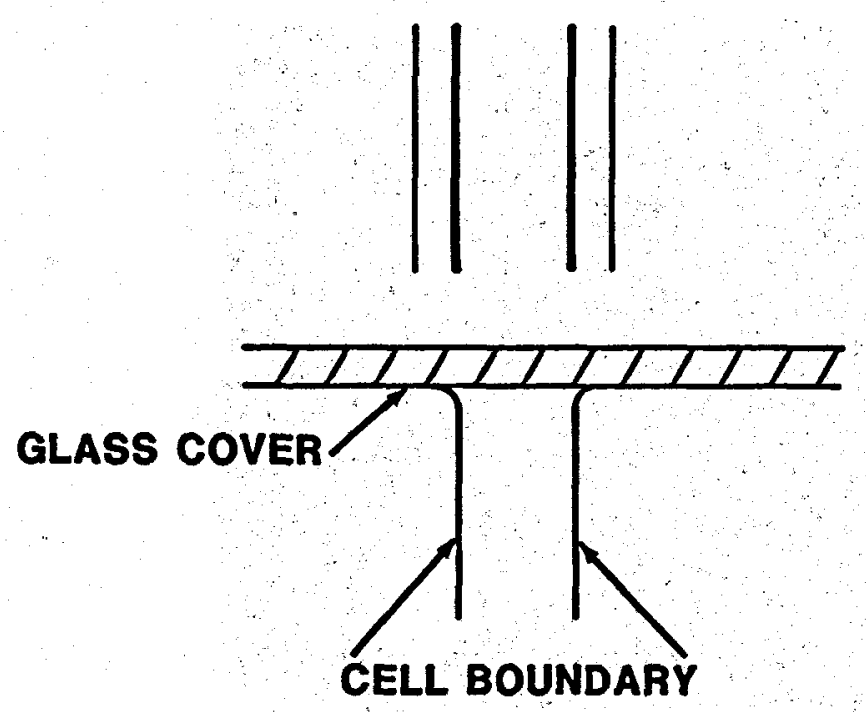

Figure 3. Schematic of Intersection Between Foam Cell and Glass Cover Plate

Figure 4 is a microphotograph of another foam sample that initially had a liquid volume fraction of 0.2 at test-section pressure. In this photograph, the microscope was focused on the third layer of foam down from the top. Deeper layers of foam are present but the focus is not sharp because of depth of field. It is apparent that $a$ wide range of cell sizes are present. Although the pentagonal dodecahedron is the supposedly preferred shape, it appears that other shapes are also present. This photograph shown in Figure 4 was taken approximately $30 \mathrm{~min}$ after the foam sample was drawn. Figures 2 and 4 are both photographs of foam samples that had been allowed to set for 9.5 and 30 minutes, respectively.

It was postulated that a flowing foam might look quite different from a static foam sample such as those illustrated in Figures 2 and 4. To investigate this concept, the foam was photographed next under conditions wherein the foam was brought to rest without substantially altering the test-section pressure and hence liquid volume fraction. Again, a nominal liquid volume fraction of 0.2 was used. The photograph in Figure 5 was taken through a Lucite pipe with an ID of $25.78 \mathrm{~mm}(1.015 \mathrm{in}$.) and $\mathrm{OD}$ of $51.0 \mathrm{~mm}(2.0 \mathrm{in}$.); the vertical centerline of the camera was approximately aligned with the vertical centerline of the pipe. The magnification of the bubbles shown in the photograph was approximately $15 X$. Initially, the foam was flowing at a liquid volume fraction of 0.2 ; then valves upstream and downstream of the Lucite test section were manually closed, and the nonflowing foam was photographed (Figure 5) at test-section pressure. Note the significant difference in the foam structure between Figures 2 and 4 (static foam) and the no-flow photograph of Figure 5. It appears that the cells of Figure 5 are more nearly spherical, the distance between adjacent cells is greater (thicker cell boundary, possibly), and the overall appearance is more like solid spheres moving in a liquid. The cell size is in the range of 0.127 to $0.889 \mathrm{~mm}(0.005$ to $0.035 \mathrm{in}$.). Although the liquid volume fraction is greater for Figure 5 than either Figures 2 or 4 , it is felt that there is a basic difference in the foam structure.

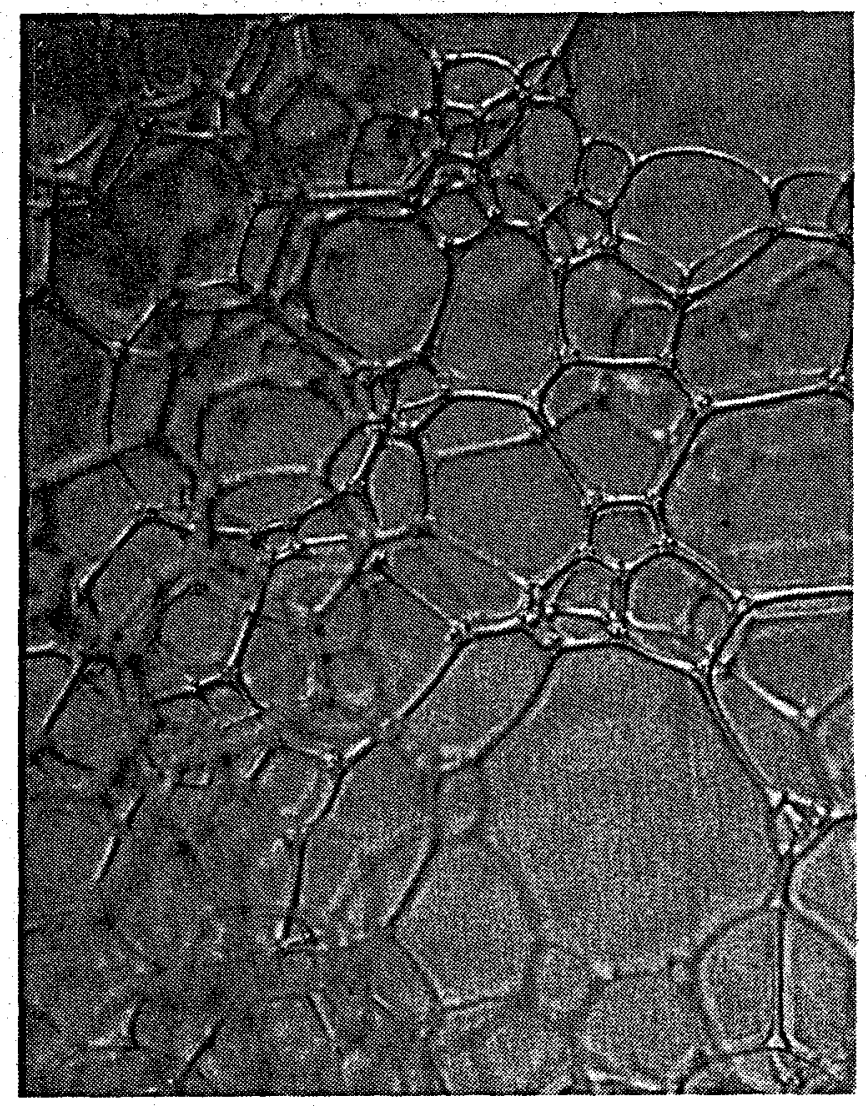

Figure 4. Microphotograph of Foam Sample Focused on Third Foam Layer Down 


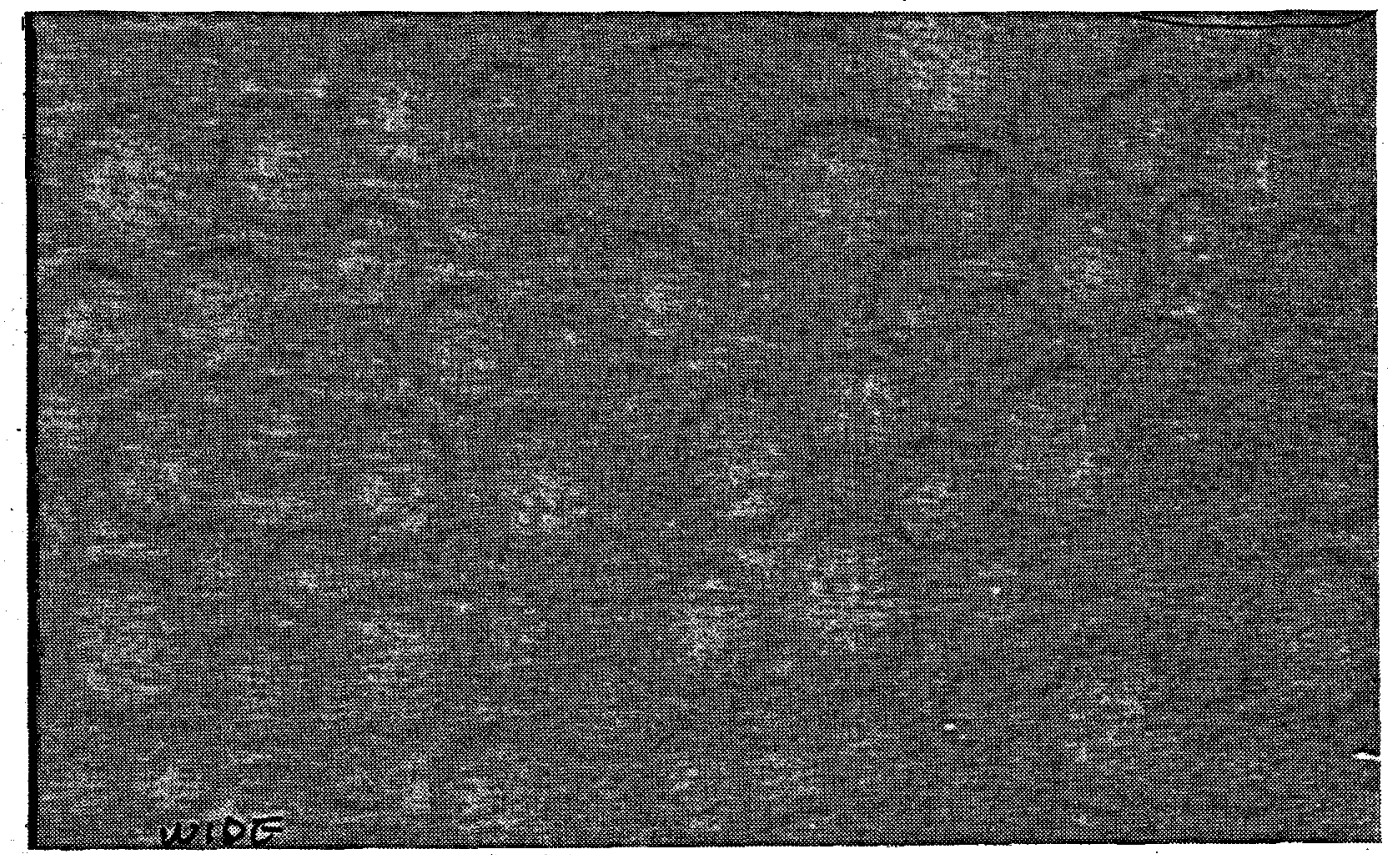

Flgure 5. Photograph (15X) of Foam Sample $(\phi=0.2)$ Brought to Rest While Maintaining TestSection Pressure

Next, the foam moving with a bulk velocity of 0.19 $\mathrm{m} / \mathrm{s}(0.64 \mathrm{ft} / \mathrm{s})$ was photographed through the Lucite test section; the results are presented in Figure 6 wherein the flow direction is from top to bottom in the photograph. Because of the foam motion, the focus in Figure 6 is not as sharp as that of Figure 5. There appear to be subtle differences between the no-flow and the flow photographs. In the flowing case, there is not as much separation distance between adjacent cells and it appears that some cells ride under adjacent cells. Or, one might think of the cells shifting relative to one another due to the velocity gradient near the wall. It is thought that the presence of an axial pressure gradient in the flowing case could also cause differences in structure. The cell-size distribution does not appear to be grossly different between the noflow and the flow cases.
In summary, it appears that the structure of a foam under flowing conditions will be dependent upon the magnitude of the axial pressure gradient. In fact, although photographs were taken at only one flow rate (pressure gradient), it is suspected that the structure will depend on the magnitude of the axial pressure gradient, the system pressure, and the liquid volume fraction. Comparison of Figures 5 and 6 indicates that the wall shearing action distorts the cell shape in the flow direction and causes the individual cells to push each other out of the way and/or slide over the top of the cell immediately in front. One can conclude that the dynamics of flowing densely packed bubbles (cells) cannot be inferred from the structure of static foam. 


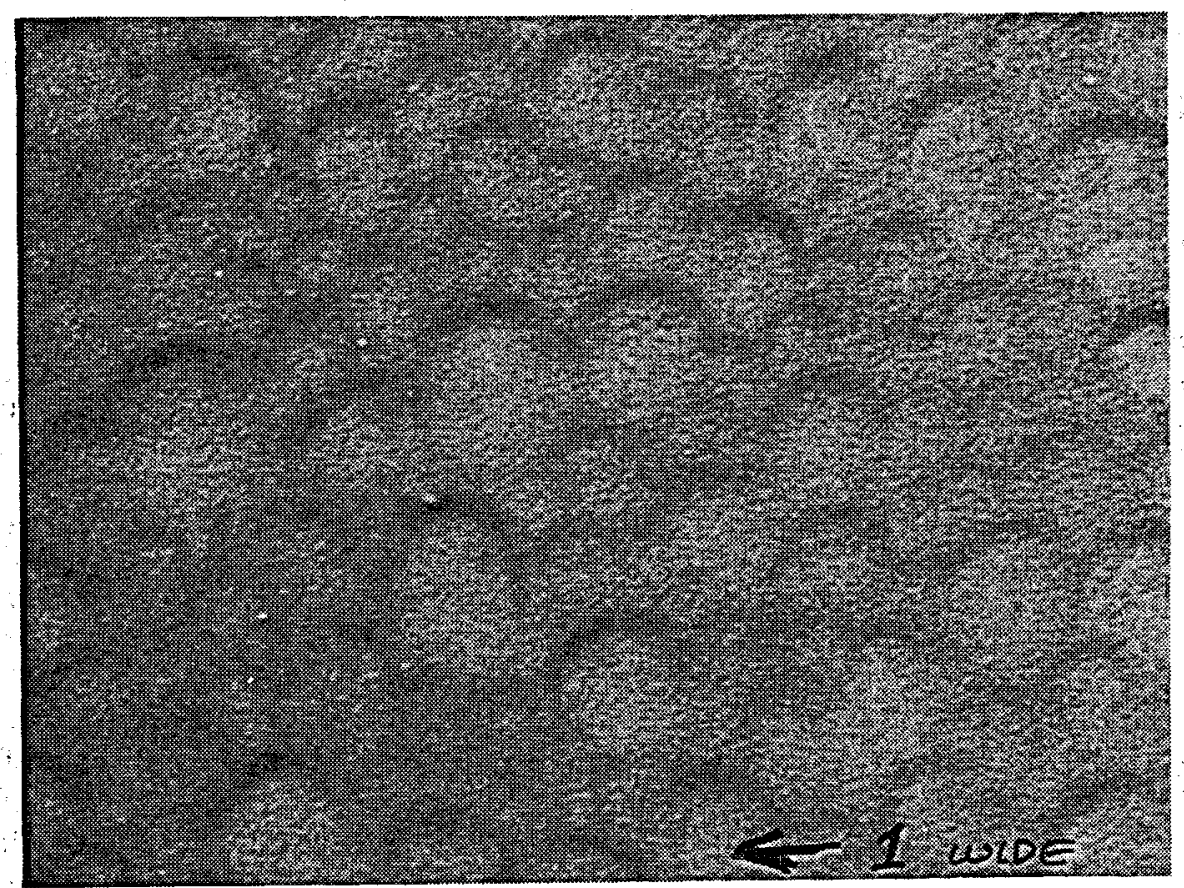

Figure 6. Photograph (15X) of Flowing $(0.64 \mathrm{ft} / \mathrm{s})$ Foam Sample $(\phi=0.2)$ 


\section{Velocity Profile Models}

Many investigators have proposed that aqueous foams exhibit a yield stress. For flow in a pipe, the existence of a yield stress implies that near the centerline, where the local shear stress may be below the yield stress, a region of uniform velocity. (plug flow) will exist. In the wall region where the local shear stress is maximum and may be greater than the yield stress, a velocity gradient will exist. The Bingham plastic fluid model contains a yield stress. Some investigators have assumed that aqueous foams behave as a "power-law" fluid. A combination of the power-law and Bingham plastic fluid models is the BulkleyHerschel model, in which shear stress and velocity gradient are related by

$\tau-\tau_{y}=\eta\left(\frac{r_{w}}{\bar{u}} \frac{d u}{d r}\right)^{n-1} \frac{d u}{d r}$

where

$\overline{\mathbf{u}}=$ the average velocity,

$r_{w}=$ the pipe radius,

$\mathrm{n}=$ the power-law exponent,

$\eta=$ the viscosity,

$\tau_{y}=$ the yield stress.

If $\mathbf{n}=1$, the Bulkley-Herschel model reduces to the Bingham plastic; further, if $\tau_{y}=0$ also, then we have the laminar Newtonian model.

Combining Equation (3-1) with the momentum equation for steady flow in a tube,

$\frac{1}{r} \frac{d}{d r}(r \tau)=\frac{\Delta p_{i}}{L}$

the velocity profile can be determined and is

$\frac{u}{u_{\mathrm{CL}}}=\left\{\begin{array}{l}1-\left(\frac{\mathrm{r}^{+}-\mathrm{c}}{1-\mathrm{c}}\right)^{\mathrm{m}+1}, \mathrm{r}^{+} \geq \mathrm{c} \\ 1, \mathrm{r}^{+}<\mathrm{c}\end{array}\right.$

where $c$ is the ratio of yield stress to wall shear stress and $m=1 / n$. An alternative way of writing the velocity profile is to normalize the local velocity by the average velocity:

$$
u^{+}=\frac{u}{\bar{u}}=\left\{\begin{array}{cc}
\frac{1-\left(\frac{r^{+}-c}{1-c}\right)^{m+1}}{1-\frac{2(1-c)}{m+2}+\frac{2(1-c)^{2}}{(m+2)(m+3)}}, & r^{+} \geq c \\
\frac{1}{1-\frac{2(1-c)}{m+2}+\frac{2(1-c)^{2}}{(m+2)(m+3)}}, & r^{+}<c
\end{array}\right.
$$

Figure 7 presents the dimensionless velocity profile for $\mathrm{m}=1$ (Bingham plastic) and for $\mathrm{c}$ in the range 0.0 to 0.8 . The dimensionless centerline velocity increases as c decreases for a fixed value of $\mathrm{m}$. Figure 8 presents the dimensionless velocity profile for the Bulkley-Herschel fluid with $m=2$. For a given value of $c$, increasing $m$ decreases the dimensionless centerline velocity. For a given value of $c$, the profile shape is very sensitive to changes in $\mathrm{m}$. If the dimensionless centerline velocity $u_{\mathrm{CL}}^{+}$is specified, then Equation (34b) can be used to relate $c$ to $\mathrm{m}$; this result is

$$
\begin{aligned}
c=1 & -\frac{1}{2}[\mathrm{~m}+3 \\
& \left.-\sqrt{(m+3)^{2}-2(m+3)(m+2)\left(1-1 / u_{\mathrm{CL}}^{+}\right)}\right] .
\end{aligned}
$$

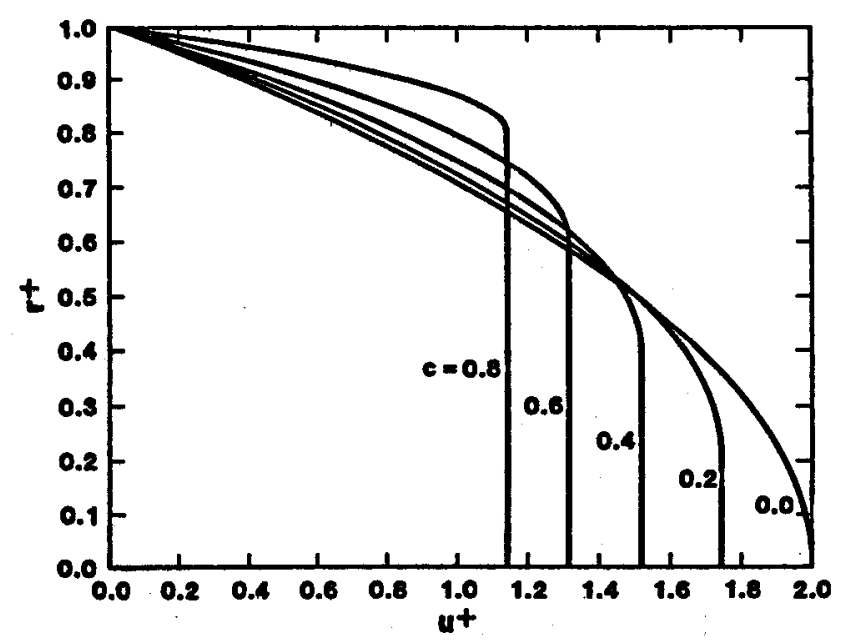

Figure 7. Dimensionless Velocity Profile for Bingham Plastic $(m=1)$ with $c=0.0$ to 0.8 


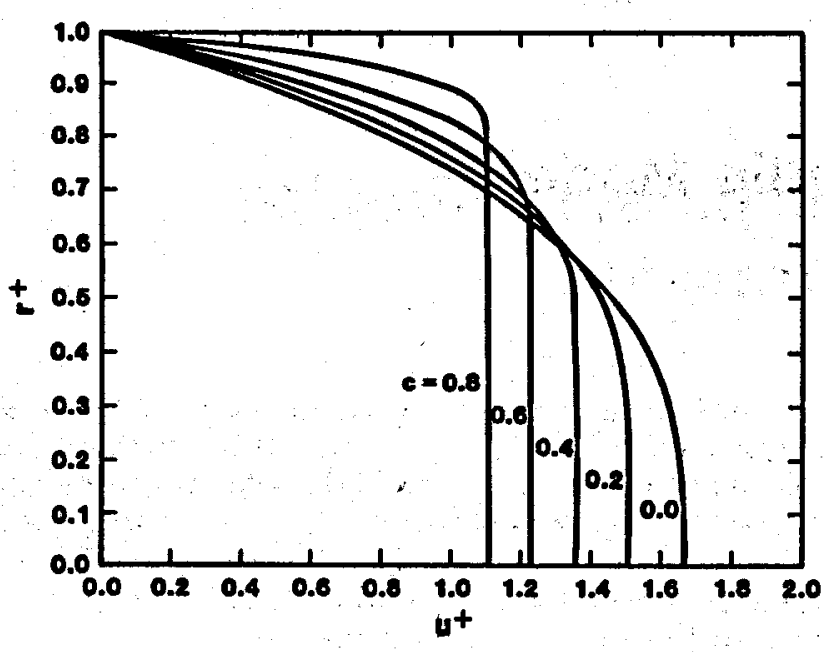

Figure 8. Dimensionless Velocity Profile for BulkleyHerschel Fluid $(m=2.0)$ for $c=0.0$ to 0.8

Figure 9 presents five dimensionless velocity profiles $(m=1-5)$ for the Bulkley-Herschel fluid, all having $u_{\mathrm{CL}}^{+}=1.4$. If the centerline velocity is the same for these profiles, then they will also have the same mass flow rate. For a given mass flow rate and centerline velocity, the results of Figure 9 indicate that the velocity profile is not very sensitive to the value of $m$, the power-law exponent. Consequently, an experimentally determined velocity profile cannot be used to reliably determine the value of the power law that best fits the velocity-profile data. This point will be touched on in greater detail in a subsequent section. In terms of sensitivity coefficient ideas, this means that the partial derivative of the velocity with respect to the power-law exponent $m$ is very small. The velocity gradient at the wall is also very insensitive to changes in $\mathbf{m}$.

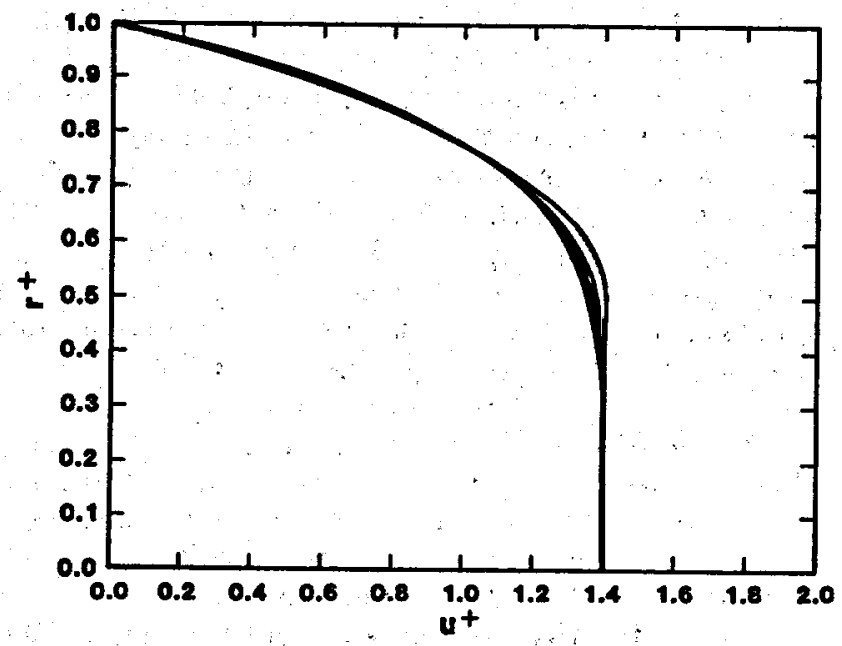

Figure 9. Dimensionless Velocity Profiles for $m=1$ to 5 , All Having $u_{\mathrm{cl}}^{+}=.1 .4$ 


\section{Predictions of Temperature Profiles and Heat Transfer}

A large viscosity is one of the properties that make aqueous foams a candidate for a geothermal drilling fluid. The pressure-drop experiments of Blackwell and Sobolik ${ }^{2}$ indicated that the Reynolds number is in the range 10 to 100 and the flow would be laminar for practical operating conditions. For laminar pipe flow, the number of diameters required to reach a fully developed velocity profile is approximately $\mathrm{Re} / 20$. Consequently, for $\operatorname{Re}=100$, only five pipe diameters are required for the velocity profile to become fully developed. Throughout this report, it will be assumed that the velocity profile is fully developed.

Since foam is mainly gas (on a volume basis), the thermal diffusivity will be closer to that of the gas phase than the liquid phase. Consequently, heat does not diffuse very rapidly in foams. The Prandtl number, which is the ratio of momentum diffusivity to thermal diffusivity, will be large (of the order of 1000 or greater). For a fluid with a large Prandtl number, the thermal boundary layer will develop much more slowly than the velocity boundary layer. To develop some insight into heat transfer in high Prandtl number fluids, some of the results of Bird, Armstrong, and Hassager $^{3}$ will be used. The energy equation for laminar tube flow without axial conduction or viscous dissipation can be written as

$\rho \mathrm{C}_{\mathrm{p}} \mathrm{u}(\mathrm{r}) \frac{\partial \mathrm{T}}{\partial \mathrm{x}}=\mathrm{k} \frac{1}{\mathrm{r}} \frac{\partial}{\partial \mathrm{r}}\left(\mathrm{r} \frac{\partial \mathrm{T}}{\partial \mathrm{r}}\right)$.

For $\mathrm{Pe}=\overline{\mathrm{u}} \mathrm{D} / \alpha$ greater than about 10 , the effects of axial conduction can be ignored. Numerical analyses by the authors have shown that viscous dissipation can be ignored for the conditions of this report. The inlet and boundary conditions for Equation (4-1) are uniform inlet temperature, fixed wall temperature, and symmetry at the centerline:

$T(0, r)=T_{i}, \quad T\left(x, r_{w}\right)=T_{0}, \quad \frac{\partial T(x, 0)}{\partial r}=0$.
Bird, Armstrong, and Hassager ${ }^{3}$ assumed that the thermal boundary layer is much thinner than the velocity boundary layer; hence, the velocity profile can be assumed linear with distance from the wall and the effects of wall curvature could be ignored. These assumptions allow one to obtain a closed form expression for the local Nusselt number:

$\mathrm{Nu}_{\mathrm{z}}=\frac{2^{4 / 3}}{9^{1 / 3} \Gamma(4 / 3)}\left(\mathrm{x}^{+}\right)^{-1 / 3}\left(-\left.\frac{1}{4} \frac{d \mathrm{u}^{+}}{\mathrm{dr}^{+}}\right|_{\mathbf{r}^{+}=1}\right)^{2 / 3}$

where $\Gamma()$ is the Gamma function, $u^{+:}=u / \bar{u} ; r^{+}=$ $r / r_{w}$, and $x^{+}=\left(x / r_{w}\right) / P e$. This approximate result indicates that the local heat-transfer coefficient falls off with distance from the leading edge to the $1 / 3$ power and all of the velocity-profile information is contained in the velocity gradient at the wall. From the velocity profile for the Bulkley-Herschel fluid model, the velocity gradient at the wall can be written as

$$
\begin{aligned}
-\left.\frac{1}{4} \frac{\mathrm{du}^{+}}{d \mathrm{r}^{+}}\right|_{\mathrm{r}^{+}=1} & =\frac{\frac{1}{4}\left(\frac{\mathrm{m}+1}{1-\mathrm{c}}\right)}{1-\frac{2(1-\mathrm{c})}{\mathrm{m}+2}+\frac{2(1-\mathrm{c})^{2}}{(m+2)(\mathrm{m}+3)}} \\
& =\mathrm{g}^{3}(\mathrm{c}, \mathrm{m}) .
\end{aligned}
$$

Table 1 tabulates the dimensionless velocity gradient and the function $g(c, m)$ as a function of $c$ for several values of the power law exponent $m$. For a given value of $m, g(c, m)$ and hence the local Nusselt number do not vary significantly with $c$, provided $c$ is less than about 0.4. When $c$ approaches unity (plug flow), then the local Nusselt number is very sensitive to $\mathrm{c}$. 
Table 1. Dimensionless Velocity Gradient and the Function $g(c, m)$ as Functions of $c$ for Several Values of the Power-Law Exponent, $m$

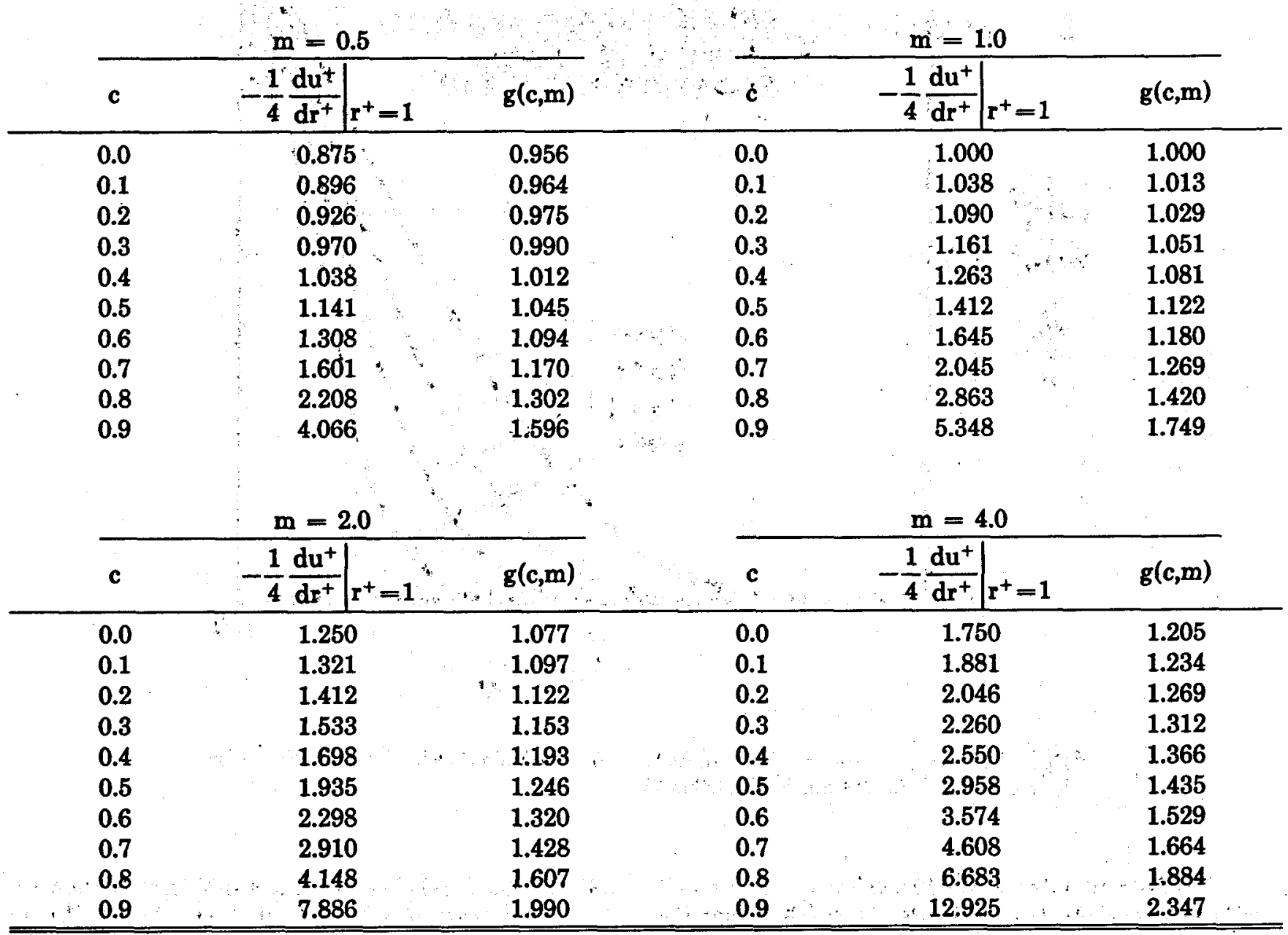

Figure 9 presents the family of velocity profiles that have the same mass flow rate but different values of (c,m). From this plot, it is obvious that the dimensionless velocity gradient at the wall varies only slightly. Therefore, the local Nusselt number will not be terribly sensitive to the velocity profile, provided the assumptions of Equation (4-3) are valid.

The development of the temperature profile for a fully developed velocity profile is the classical Graetz problem. This problem has been solved by Blackwell ${ }^{4,5}$ for the Bingham plastic fluid by a separation of variables technique. The eigenvalues and eigenfunctions associated with the separation of variables solution of
Equation (4-1) were numerically determined by means of the SLEIGN code, which was developed by Bailey. ${ }^{6}$ The boundary conditions were those given by Equation (4-2). Figure 10 presents temperatureprofile predictions at the end of $3-\mathrm{m}(9.84 \mathrm{ft})$ isothermal wall pipe for $\mathrm{Pe}$ in the range 10,000 to 100,000. The velocity profile used was laminar Newtonian $(c=0.0, m=1.0)$. Calculations were also performed for $(c=0.2, m=1.0)$ and an overlay of the plots showed no discernable difference. Consequently, the velocity profile will not drastically alter the temperature profile for small values of $c$. 


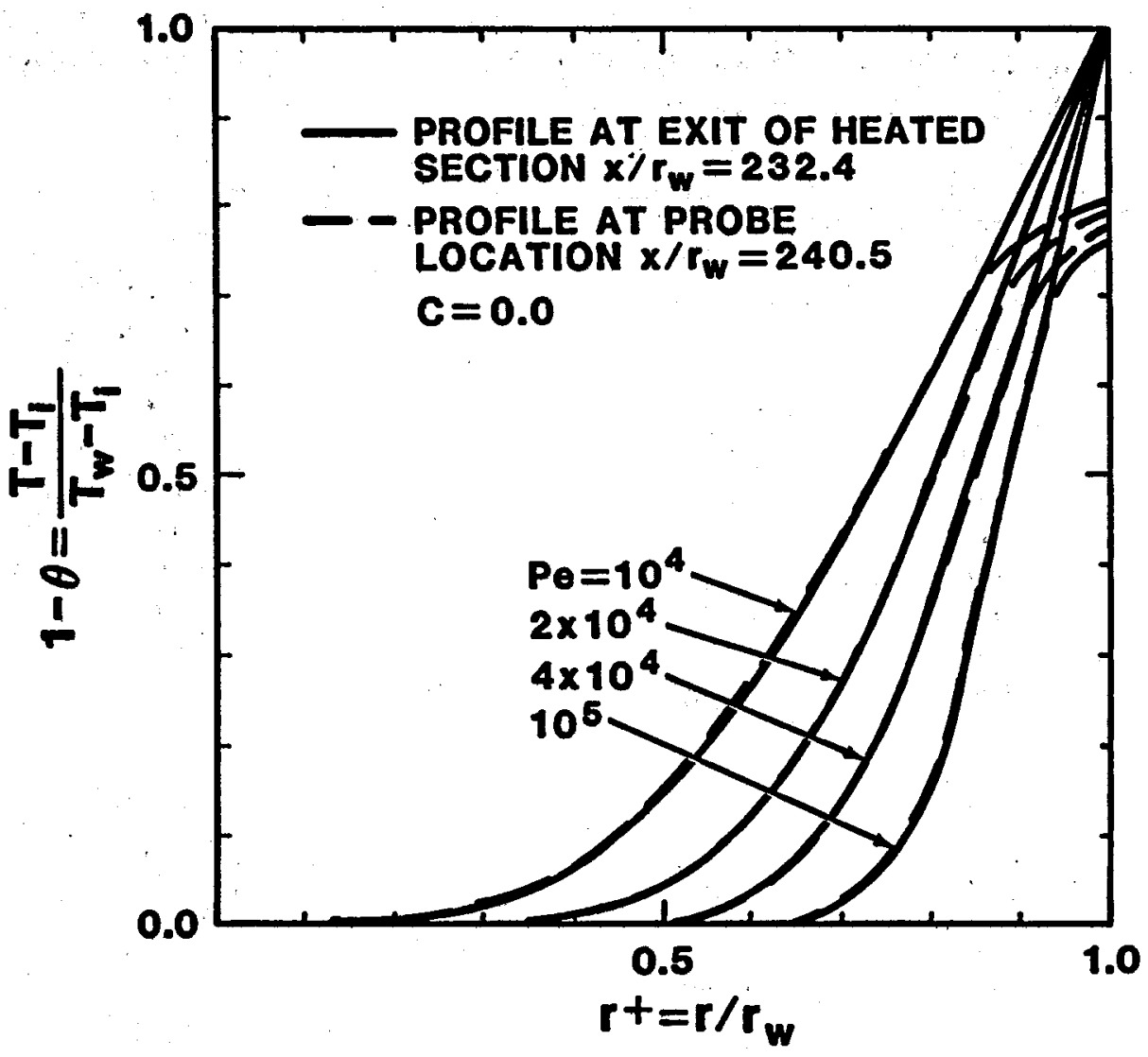

Figure 10. Temperature Profile Predictions at the End of a 3-m Isothermal-Wall Test Section and at Downstream Probe Location

The temperature profile predictions in Figure 10 exhibit several important points: 1) at the higher $\mathrm{Pe}$ values, there is a definite boundary-layer character, 2) the boundary-layer thickness is inversely proportional to the $\mathrm{Pe}$, and 3 ) the temperature profile is very nearly linear in the wall region. The near-linearity may allow one to estimate the local Nusselt number from temperature-profile measurements.

The experimental configuration (discussed in Appendix A) allowed temperature-profile measurements to be made at a distance of 9.25-cm (3.64-in.) downstream of the end of a 3-m (9.84-ft) heated pipe. This unheated section was designed to be nearly adiabatic. The analytical predictions of Blackwell $^{4,5}$ were extended to include a short adiabatic section of chlorinated polyvinyl chloride (CPVC) pipe downstream of the isothermal-wall test section. In this adiabatic section, the temperature profile redistributes itself while maintaining a constant bulk temperature. The results of this series of calculations are also shown in Figure 10. Note that both boundary conditions for the CPVC section are adiabatic. The adiabatic boundary condition at the pipe wall alters the temperature profile quite drastically, even though the flow length is only
$9.25 \mathrm{~cm}$ (3.64 in.). However, a significant portion of the temperature profile is unaltered. The results of this series of calculations suggests that the temperature gradient at the end of the heated section can be estimated from experimental temperature-profile measurements within an adiabatic section located slightly downstream. However, the wall temperature variation with position in the adiabatic section is substantial and errors in probe position will have considerable impact on the predicted temperature profile at the probe location.

The model presented in the previous section is somewhat idealized in that the boundary condition for the 3-m (9.84-ft) test section is a specified uniform wall temperature while that for the downstream section is adiabatic. In reality, both boundary conditions are considerably more complicated. Figure 11 is a schematic of a more realistic thermal model of the test section; the details of the experimental configuration will be presented in Appendix A. The foam is heated by hot water flowing around the outside of the stainless-steel pipe $(2.588-\mathrm{cm}$ ID by $0.6033-\mathrm{cm}$ wall, 1.019-in. ID by 0.2375 -in. wall). The hot water inlet and outlet bulk temperatures are measured. The heat 
flux from the hot water to the exterior of the test section was calculated from the convective heattransfer coefficient for annulus flow (based on measured flow rate) and a linear variation of the bulk fluid temperature between the inlet and outlet measured values. Since the test section was buried in an insulated box, it was assumed that the outer surface of the annulus was adiabatic. The CPVC section downstream of the stainless-steel pipe was allowed to lose heat to the ambient temperature through an overall heat-transfer coefficient $U$; the value of $U$ was calculated for steady-state conduction through the insulated box surrounding the test section.

A Finite-Control-Volume (FCV) model of the schematic shown in Figure 11 was developed; the details are presented in Appendix B. This procedure conserves energy on control volumes of finite size, assuming that the velocity profile is known. The exponetial differencing scheme of Spalding ${ }^{7}$ was used. The grid consisted of 46 radial elements by 29 axial elements for a total number of unknowns of 1410; the Peclet number was 10,000 . To verify the computer code, the boundary conditions were changed to specified wall temperature for the inner surface of the stainless-steel pipe (see Figure 11) and adiabatic wall for the CPVC pipe; these boundary conditions corresponded to the more accurate results presented by Blackwell $^{5}$ using the SLEIGN code of Bailey. ${ }^{6}$ The SLEIGN code predicts that the dimensionless wall temperature falls from 1:0 to 0.80268 in a distance of $9.25 \mathrm{~cm}$ (3.64 in.); the FCV code predicts that the wall temperature falls to 0.79729 for an error of $0.7 \%$. With grid refinement, it is anticipated that the agreement could be improved; however, it was felt that these calculations verified the FCV computer code.

Next, the more realistic boundary conditions of Figure 11 were applied and temperatures vs. time were predicted for conditions corresponding to experimental Run 30A; see the legend of Figure 12 for the detailed flow conditions. In the FCV model, conduction within the solid phase is transient while that within the foam (fluid) phase was steady state. The foam thermal conductivity was taken to be a weighted average of the gas and liquid phase thermal conductivities:

$$
\mathrm{k}=\phi \mathrm{k}_{\ell}+(1-\phi) \mathrm{k}_{\mathrm{g}} \text {. }
$$

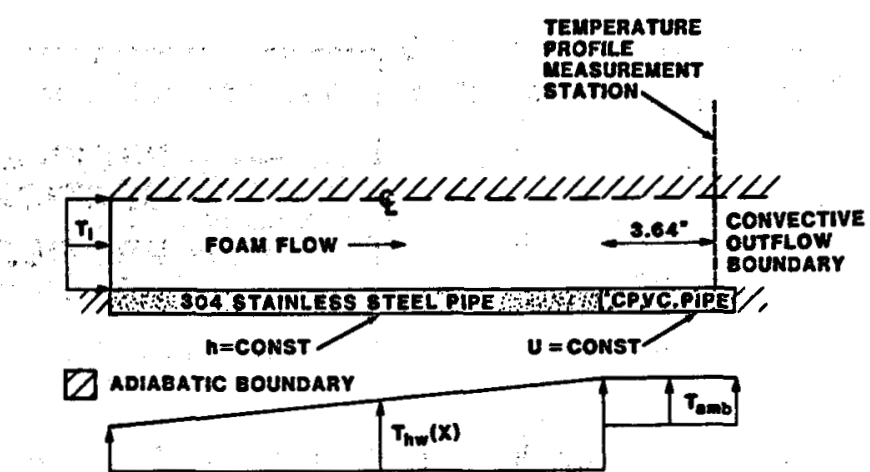

Figure 11. Schematic of Finite-Control-Volume Model for Conjugate Heat-Transfer Problem

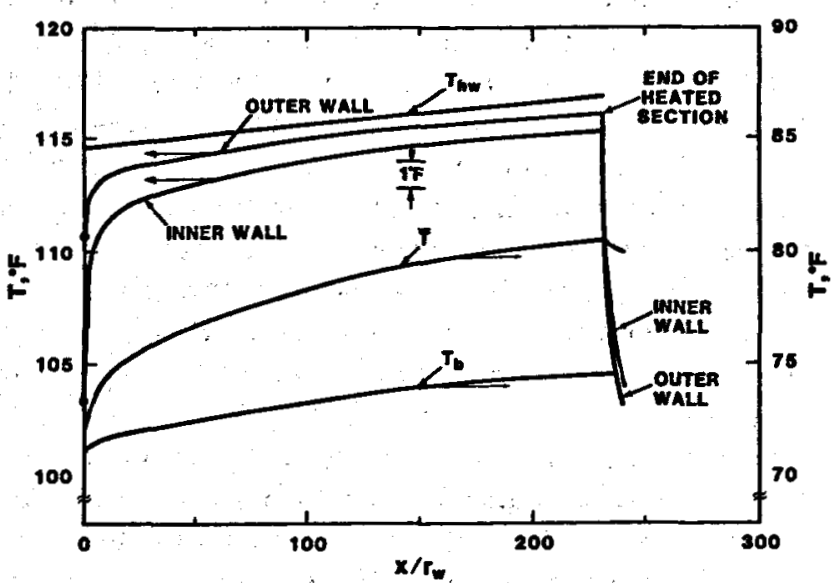

Figure 12. Numerical Predictions of Test-Section Inner and Outer Wall Temperatures, Average Foam Temperatures, and Bulk Foam Temperatures

Table 2 presents wall temperature calculations as a function of time for the temperature-probe location (9.25-cm downstream of end of heated section). These calculations indicate that steady state is reached within $4 \mathrm{hr}$, at least within practical temperature measurement accuracy. 


\section{Table 2. Transient Simulation for Run $30 \mathrm{~A}$}

\begin{tabular}{cc}
$\begin{array}{c}\text { Time } \\
(\mathrm{hr})\end{array}$ & $\begin{array}{c}\text { Wall Temperature at } \\
\left.\text { Probe Location ( }{ }^{\circ} \mathrm{F}\right)\end{array}$ \\
\hline 2.0 & 104.29 \\
4.0 & 104.63 \\
6.0 & 104.64 \\
\hline \hline
\end{tabular}

Additional details of the simulation of Run 30A are presented in Figures 12 and 13. Figure 12 presents the predicted variation of inner and outer wall temperature of the stainless-steel test section, average fluid temperature $\overline{\mathrm{T}}$, and the bulk fluid temperature $\mathrm{T}_{\mathrm{b}}$ with distance from the inlet to the heated test section. The foam enters at a uniform temperature of $21.83^{\circ} \mathrm{C}\left(71.29^{\circ} \mathrm{F}\right)$. In the design of the experimental configuration, it was desired to provide an isothermalwall boundary condition. This was to be achieved by having the thermal capacity rate $\left(\dot{m} C_{p}\right)$ of the hot water to be much larger than that for the foam. For this case, the temperature drop of the hot water would be much smaller than the temperature rise of the foam. From the wall temperature predictions, there was a significant variation in inner wall temperature with position, especially within the first 20 pipe radii. However, the remainder of the test section was isothermal to within $0.8^{\circ} \mathrm{C}\left(1.5^{\circ} \mathrm{F}\right)$. The variation of hot water temperature with position is shown for reference. Over the majority of the test section, the temperature drop across the stainless-steel pipe wall was approximately $0.7^{\circ} \mathrm{C}\left(1^{\circ} \mathrm{F}\right)$. Had the test section been made from copper instead of stainless steel, the temperature drop would have been smaller. However, structural considerations dictated the initial choice of stainless steel instead of copper. After the heating stops, both the inner and outer wall temperatures drop very rapidly.

Both the average and bulk foam temperatures increase due to the heat addition. The average temperature increases more rapidly than the bulk temperature. In fact, the bulk temperature increases only about $1.9^{\circ} \mathrm{C}\left(3.5^{\circ} \mathrm{F}\right)$ because of the low thermal diffusivity of the foam. From an experimental point of view, a much larger increase in bulk temperature would have been desirable. After the heating stops, the average foam temperature drops slightly; however, the bulk temperature remains nearly constant because the heat loss through the CPVC section is very small.

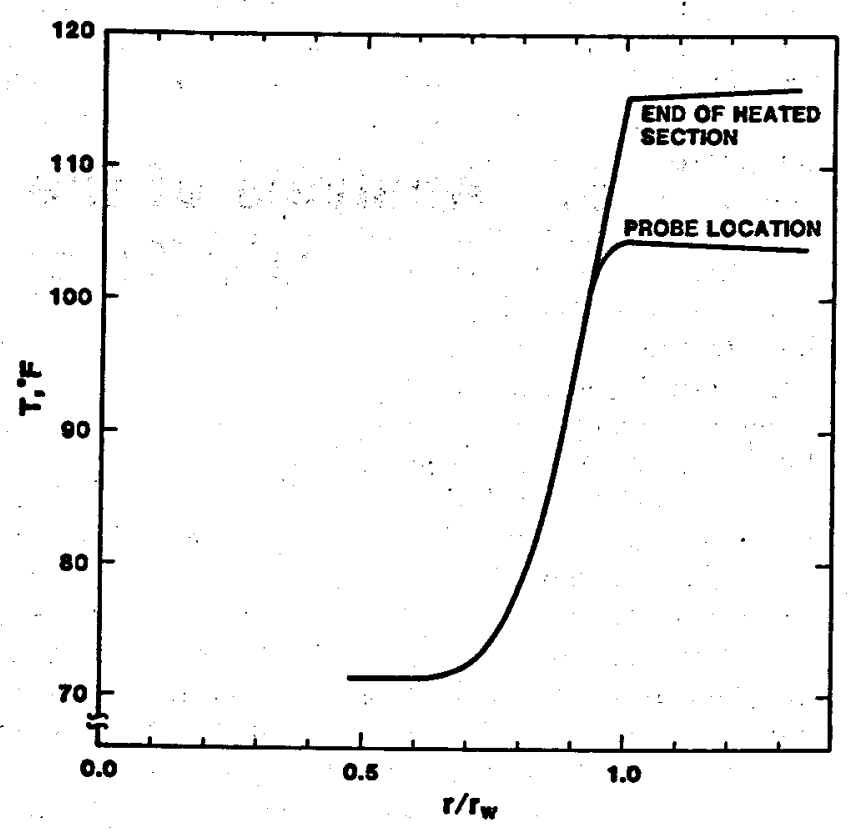

Figure 13. Predicted Temperature Profile at End of Heated Section and Probe Location, Run 30A

Figure 13 presents the predicted temperature profile for axial locations corresponding to the end of the heated section and the temperature-probe location $(9.25 \mathrm{~cm}, 3.64 \mathrm{in}$.) for Run $30 \mathrm{~A}$. The only measurable foam temperature change between the end of the heated section and the probe location occurs in the outer $90 \%$ of the pipe radius. This slow response is due to the low thermal diffusivity of the foam. The predictions indicate that the maximum foam temperature at the probe location occurs at $r / r_{w}=0.99$; however, this maximum is not sufficiently large to resolve experimentally.

In summary, the computer model has identified important features to look for in the experimental data. It also gives a better feel for how nearly one can maintain the wall of the test section at an isothermal temperature and pointed out the importance of knowing probe location since the axial temperature gradients are quite steep within the CPVC section. 


\section{Analysis of the Experimental Velocity and Temperature Data}

Velocity and temperature profiles were measured with micrometer-adjusted traversing probes. For the velocity profiles, a TSI hot-film anemometer (Model $1261 \mathrm{~K}-10 \mathrm{AW}$ ) was used; a type $\mathrm{K}$ thermocouple probe was used for the temperature profiles. The sensing element of the hot-film probe is $0.23 \mathrm{~mm}(0.009 \mathrm{in}$.) in length and has a diameter of $0.047 \mathrm{~mm}$ (0.00185 in.). The probe was obtained from TSI. The temperature probe was formed by butt welding $0.076-\mathrm{mm}(0.003$ in.) chromel/alumel thermocouple wire and flattening the bead to $0.127-\mathrm{mm}$ ( 0.005 in.). A more complete description of the temperature probe is found in Appendix C.

The output voltages from both the velocity and temperature probes indicate a region with little or no gradient near the centerline of the test section and a region with a steep gradient near the wall. Frequent measurements, every 0.025 to $0.13 \mathrm{~mm}(0.001$ to 0.005 in.), were taken in regions of large gradients, whereas larger increments, every $1.3 \mathrm{~mm}(0.05 \mathrm{in}$.$) , were used$ in the centerline region.

Aqueous foams have very high Prandtl numbers (1000 to 20,000). As a result, the thermal entry length is much greater than the hydrodynamic entry length. The maximum Reynolds number associated with the data of this study is approximately 84 , and the corresponding maximum hydrodynamic entry length is $\mathbf{1 3}$ cm (5.1 in.). The flow is, therefore, considered laminar and hydrodynamically fully developed everywhere in the test section.

The output voltage $E$ of the hot-film anemometer is shown as a function of dimensionless radial position in Figure 14 for several flow rates. A nominal liquid volume fraction of 0.2 was used for all velocity profiles; conditions for the various runs are given in Table 3.

The voltage profiles from the hot-film probe confirm the existence of a plug flow region near the pipe centerline. Although the extent of this region is a matter of judgement, it appears that the dimensionless plug flow radius is approximately 0.5 to 0.6 for three of the four profiles. Scatter in the fourth profile

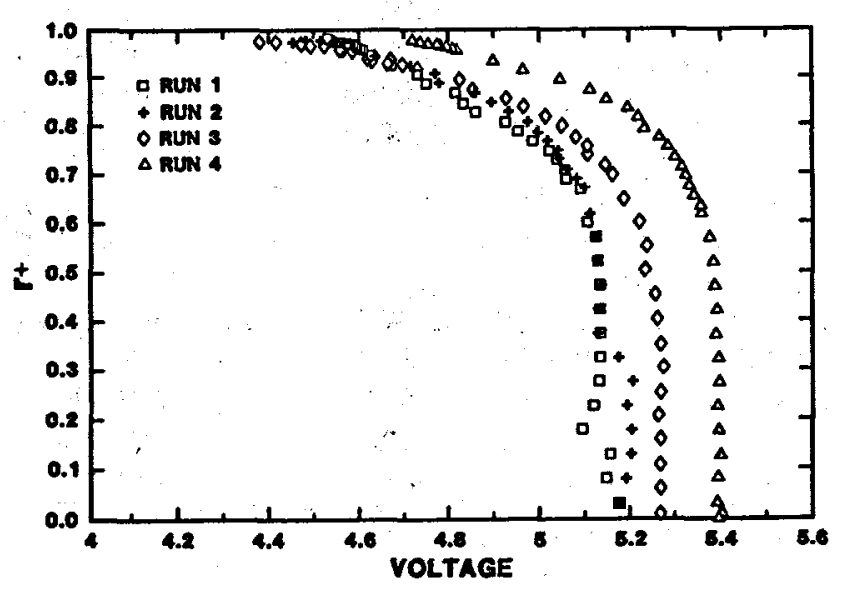

Figure 14. Hot-Film-Probe Output Voltage as a Function of Position for a Nominal Liquid Volume Fraction of 0.2 and Various Flow Rates

makes determining the corresponding plug region impractical. The plug flow region appears to be substantially larger than indicated by pressure-drop studies of Blackwell and Sobolik. ${ }^{2}$

An attempt was made to calibrate the hot-film probe using this data and a method described in Appendix D. Integration of the profile of density times velocity results in the mass flow rate, which is known experimentally for each run. A plot of the measured-vs.-calculated mass flow rates is presented in Figure D-1; there is as much as $20 \%$ variation between the calculated mass flow rate and the corresponding measured value. Little confidence is therefore placed in the calibration. One explanation is that the constants of calibration are dependent on variables besides density and velocity. Variables that could possibly affect calibration include cell size, testsection pressure, pressure gradient, and liquid volume fraction. A consistent set of constants of calibration might not exist even for all radial positions within a single flow. Figures 15 through 18 are the velocity profiles determined from the voltage data and this calibration. 


\section{Table 3. Experimental Condition for Velocity-Profile Measurements}

\section{a) SI Units}

\begin{tabular}{cccccc} 
Run & $\begin{array}{c}\text { Mass Flow } \\
\text { Rate } \\
(\mathrm{kg} / \mathrm{s})\end{array}$ & $\begin{array}{c}\text { Liquid } \\
\text { Volume } \\
\text { Fraction }\end{array}$ & $\begin{array}{c}\text { Density } \\
\left(\mathrm{kg} / \mathrm{m}^{3}\right)\end{array}$ & $\begin{array}{c}\text { Test Section } \\
\text { Pressure } \\
(\text { bars })\end{array}$ & $\begin{array}{c}\text { Test Section } \\
\text { Temperature } \\
\left({ }^{\circ} \mathrm{C}\right)\end{array}$ \\
\hline 1 & 0.0184 & 0.194 & 195 & 2.26 & 18.4 \\
2 & 0.0287 & 0.204 & 205 & 2.36 & 18.3 \\
3 & 0.0355 & 0.205 & 208 & 3.17 & 18.9 \\
4 & 0.0614 & 0.206 & 208 & 3.11 & 18.8
\end{tabular}

b) English Units

\begin{tabular}{cccccc} 
& $\left(\mathrm{lb}_{\mathrm{m}} / \mathrm{s}\right)$ & & $\left(\mathrm{lb}_{\mathrm{m}} / \mathrm{ft}^{3}\right)$ & $(\mathrm{psia})$ & $\left({ }^{\circ} \mathrm{F}\right)$ \\
\hline 1 & 2.44 & 0.194 & 12.2 & 32.8 & 65.1 \\
2 & 3.79 & 0.204 & 12.8 & 34.2 & 65.0 \\
3 & 4.70 & 0.205 & 13.0 & 46.0 & 66.0 \\
4 & 8.12 & 0.206 & 13.0 & 45.1 & 65.9 \\
\hline \hline
\end{tabular}

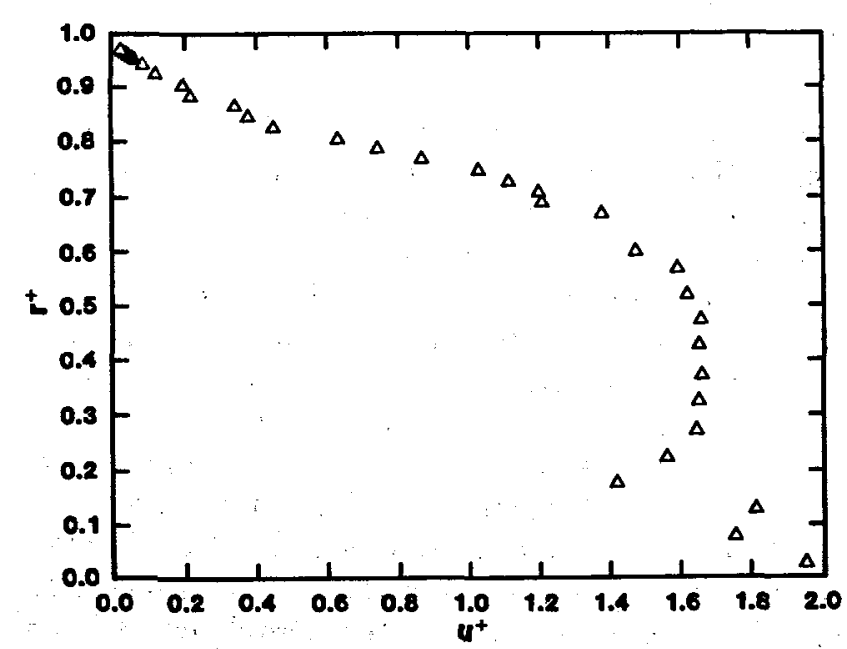

Flgure 15. Experimental Dimensionless Velocity Profile, Run $1 \mathrm{~m}=0.0184 \mathrm{~kg} / \mathrm{s}$

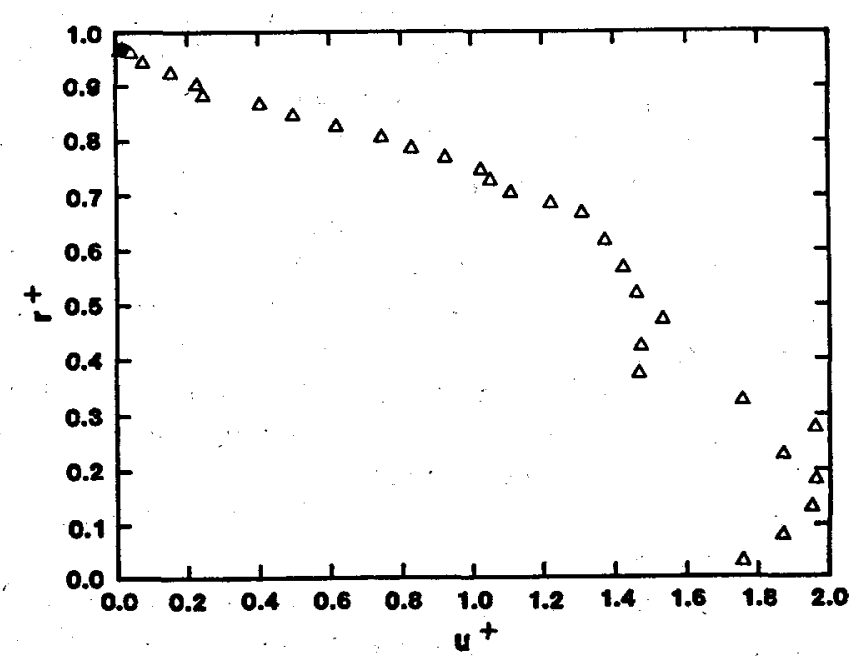

Figure 16. Experimental Dimensionless Velocity Profile, Run $2 \dot{\mathrm{m}}=0.0287 \mathrm{~kg} / \mathrm{s}$ 


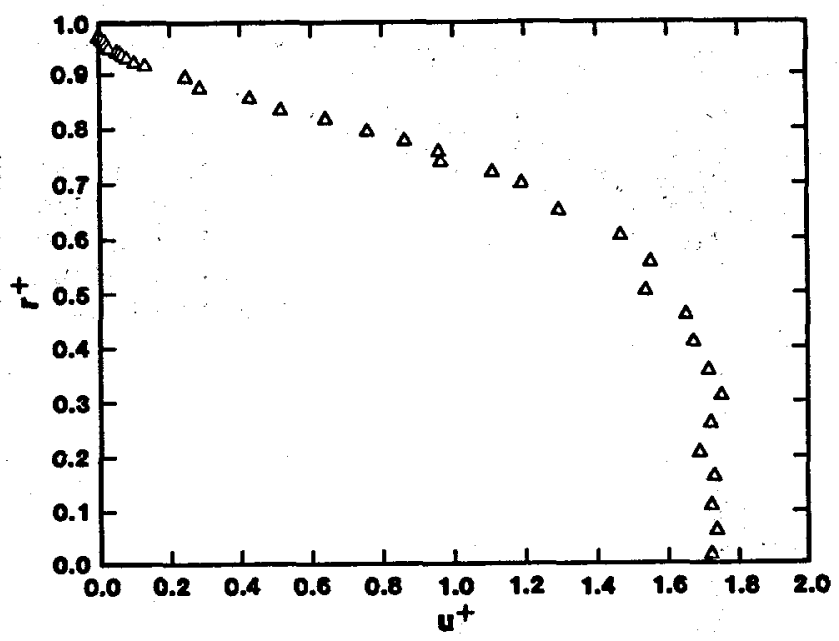

Figure 17. Experimental Dimensionless Velocity Profile, Run $3 \stackrel{\mathrm{m}}{=}=0.0355 \mathrm{~kg} / \mathrm{s}$

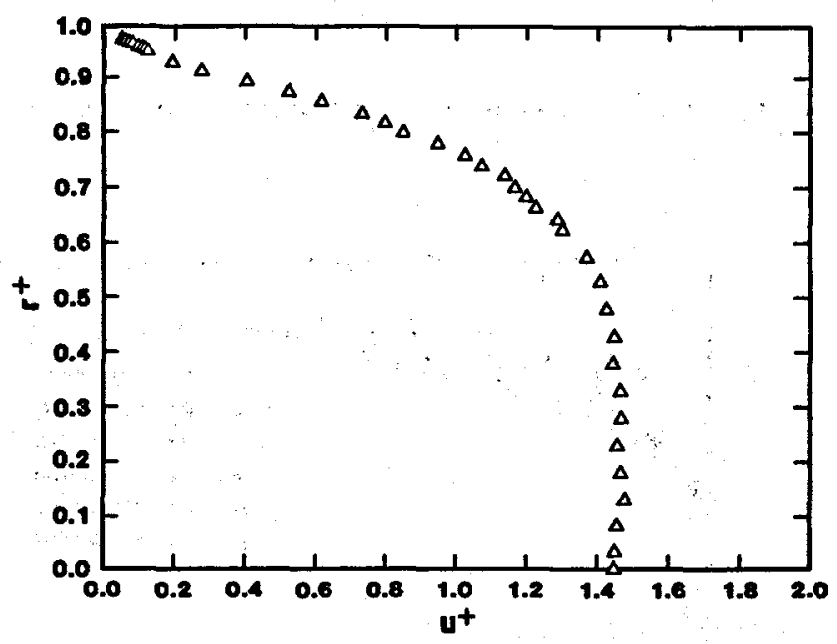

Figure 18. Experimental Dimensionless Velocity Profile, Run $4 \mathrm{~m}=0.0614 \mathrm{~kg} / \mathrm{s}$

As illustrated by Figure 9 , velocity profiles for different exponents, $m$, associated with the power-law stress-strain relationship are not very different. Due to scatter in the "data," the experimental "velocity profile" could fit any one of a family of profiles (sets of $c$ and $m$ resulting in the same dimensionless centerline velocity) equally as well. Consequently, experimental determination of the exponent, $m$, is not practical. The Bingham plastic model $(m=1)$ is preferred for its simplicity.

The calculated velocity profiles indicate that the ratio of centerline to average velocity $\left(u_{c} / \bar{u}\right)$ decreases with increasing flow rate. This trend is contrary to the expected behavior of a power-law fluid with yield; an explanation is not known. (It was expected that the yield stress would be a property of the foam dependent upon liquid volume fraction; $c$, therefore, would decrease with increasing wall shear stress or flow rate.) Also, it is not certain whether this trend is actual or the result of an incorrect calibration equation.

Another phenomenon apparent in the velocity profiles (Figures 15 to 18 ) is a change in curvature in the near-wall region. In the near-wall region, the curvature appears to be convex, whereas near the centerline, the curvature is concave. Once again, it is not clear whether this is actual or a result of the "calibration equation." The calibration assumes no slip at the wall, thereby forcing the velocity at the wall to be zero. One possible explanation is that the viscosity is variable due to the large shear-stress gradient in this region.

Temperature-profile measurements were made for liquid volume fractions ranging between 0.05 and 0.35 and velocities ranging between 0.17 and $0.85 \mathrm{~m} / \mathrm{s}$ $(0.57$ and $2.8 \mathrm{ft} / \mathrm{s})$. The liquid volume fraction and velocity ranges correspond approximately to that of field applications. Since the experimental pipe radius is smaller than that associated with the field application, the experimental Peclet number range is lower than that of the application. No extrapolation difficulties are expected, however, provided the flow remains laminar.

The experimentally measured temperature profiles are shown in dimensionless form in Figures 19 through 24. The profiles exhibit a boundary layer region near the wall; in the center region, the temperature is the same as the inlet, indicating that the flow is thermally developing for all conditions observed. Due to test-section design, profile measurements could not be taken in the heated region but instead are taken $9.25 \mathrm{~cm}$ (3.64 in.) downstream of the end of the heated section. The boundary condition for the region immediately downstream of the heated section is nearly adiabatic (see Appendix A for a description of the experimental configuration). The influence of the adiabatic wall is seen in the near-wall region where a second boundary layer is beginning to form. As expected, the extent of the boundary-layer region decreases with increasing Peclet number. (Peclet number is based on the linear thermal conductivity model; Eq. 4-5). The dimensionless temperature at the wall tends to decrease with increasing Peclet number. This phenomenon, which can also be seen in the predicted profiles shown in Figure 10, is believed to be due to the steeper temperature gradient associated with larger Peclet numbers. 


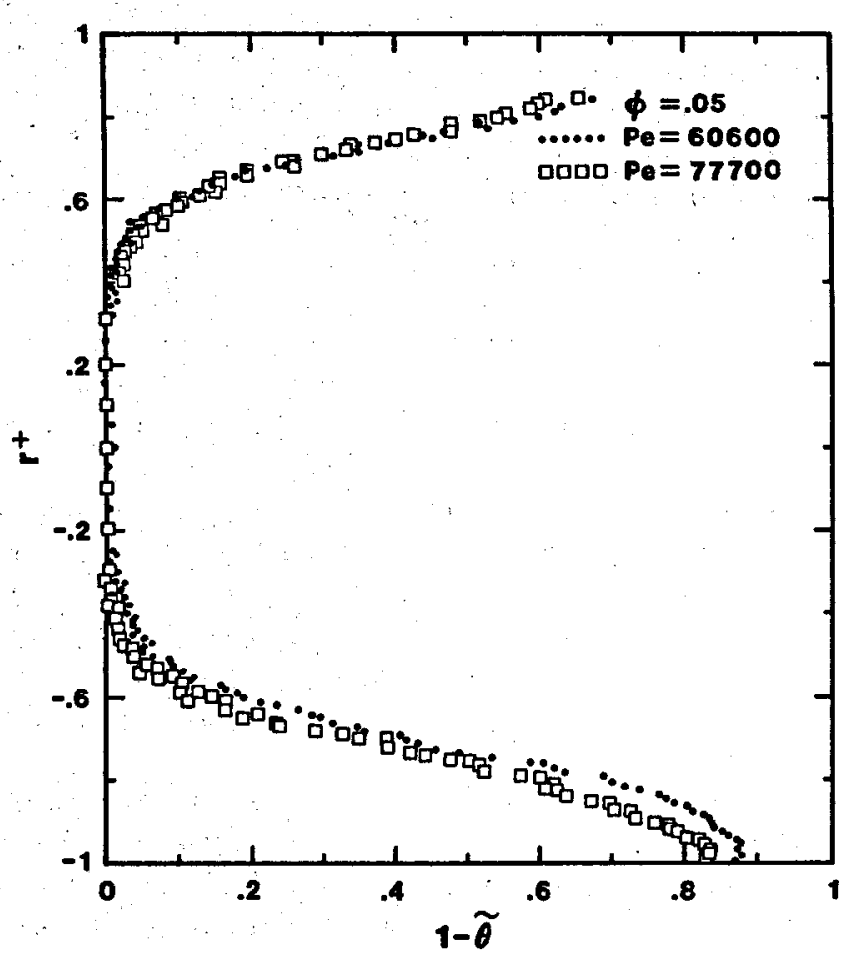

Figure 19. Dimensionless Temperature Profiles for $\phi=$ 0.05

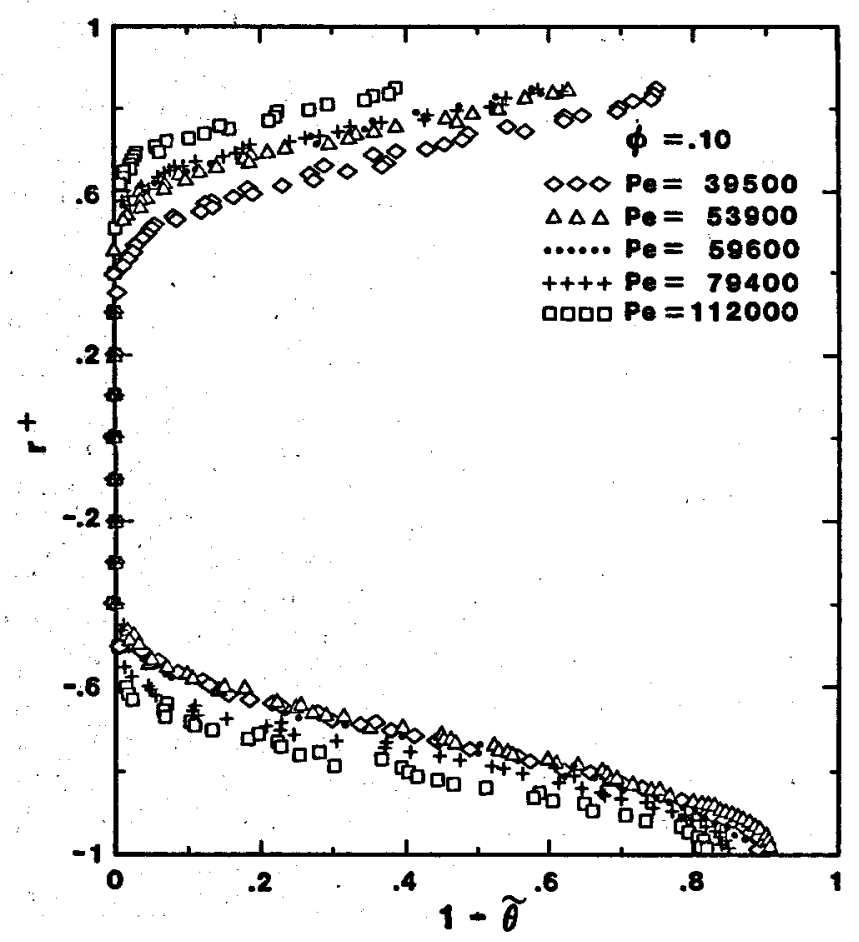

Figure 20. Dimensionless Temperature Profiles for $\phi=$ 0.10

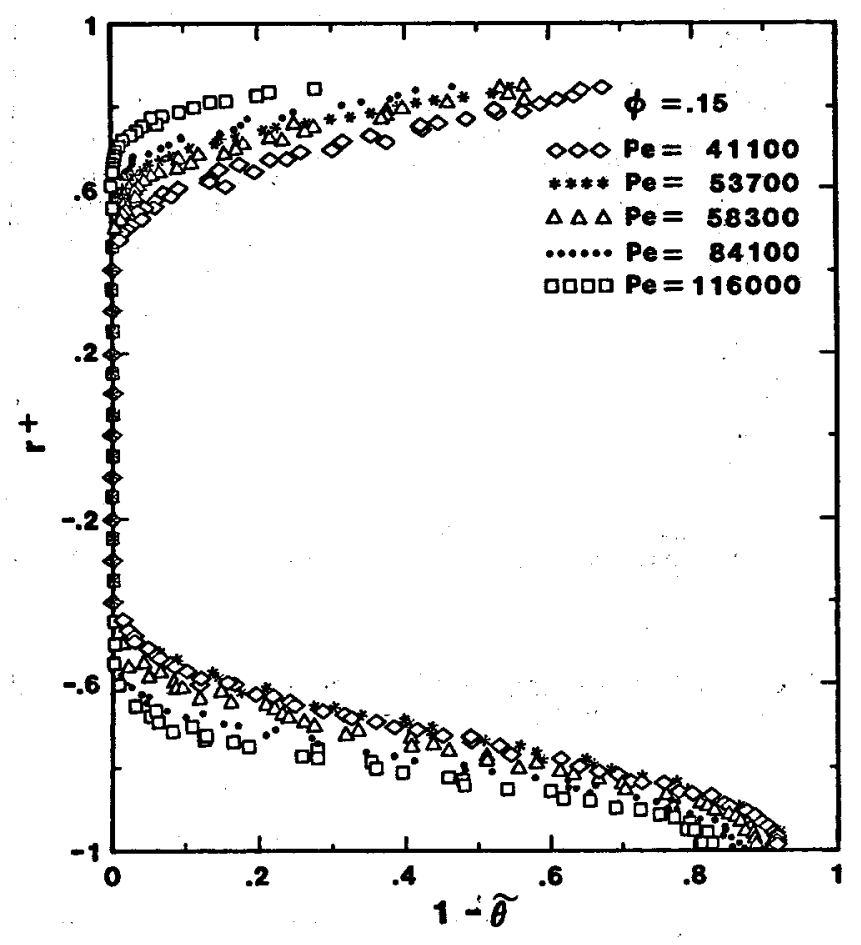

Figure 21. Dimensionless Temperature Profiles for $\phi=$ 0.15

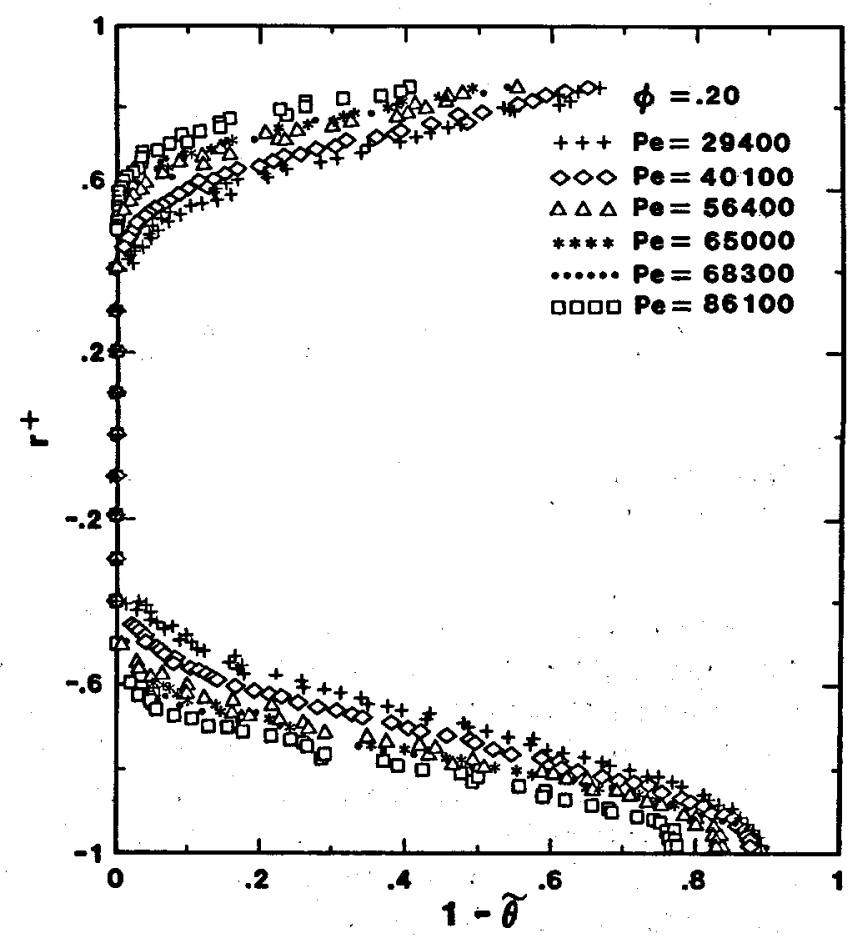

Figure 22. Dimensionless Temperature Profiles for $\phi=$ 0.20 


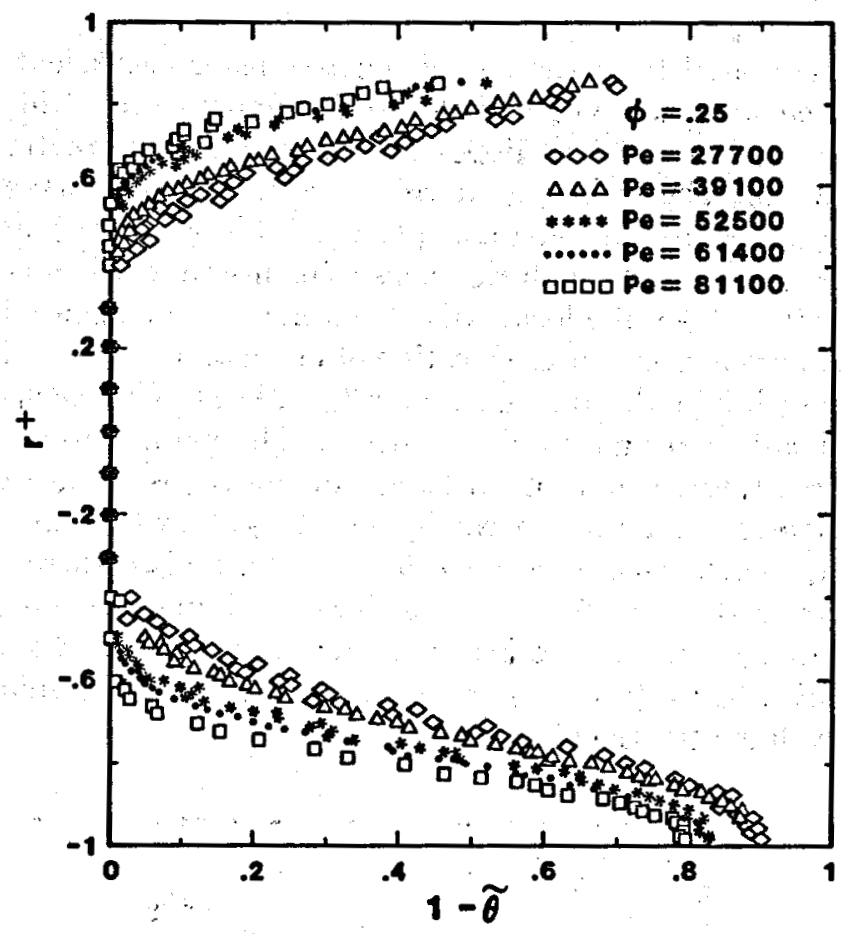

Figure 23. Dimensionless Temperature Profiles for $\phi=$ 0.25

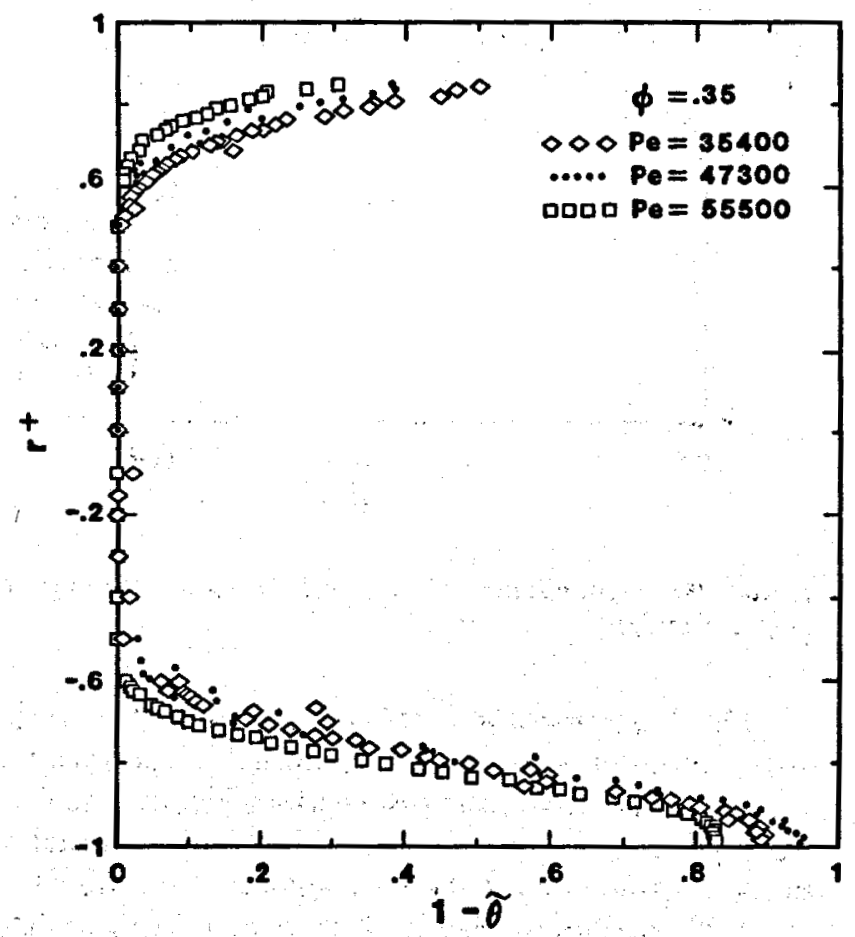

Figure 24. Dimensionless Temperature Profiles for $\phi=$ 0.35
The temperature-profile probe is small enough to react to the passage of $a$ single foam cell. In the center region, there is no temperature gradient and hence little scatter in the data. In the thermal-boundarylayer region, where the temperature gradient is steep, the passage of a foam cell results in a temperature perturbation. Therefore, the profiles exhibit significant scatter in the boundary-layer region despite the readings being averaged over approximately 200 scans. Some of the profiles are quite symmetrical while others are asymmetrical about the pipe centerline. A fully satisfactory reason for the variation in symmetry between profiles has not been found. One possible explanation is that the foam is not homogeneous through the test section; asymmetry could result if the cell size or liquid volume fraction varies as either a function of time or position. The presence of the temperature probe can also introduce asymmetries due to flow blockage. Maximum blockage occurs when the probe touches the pipe wall opposite the side in which the probe is inserted, and decreases as the probe is traversed across the pipe cross-section.

The 0.95 thermal-boundary-layer-thickness $\left(\delta / r_{w}\right)$ variation with the Peclet number for the data is shown in Figure 25. The data was determined graphically from the temperature-profile data using a French curve to "smooth" the profiles. A suitable criterion for the boundary-layer thickness must be chosen; the 0.99 criterion often used in analytical studies would have much more experimental error. Therefore, the 0.95 criterion is deemed more suitable for the present study.

A line passing through the data would be roughly parallel to the analytical results for Bingham plastics with $c=0$ and $c=1$; however, the flow is much more thermally developed than was predicted. One explanation is that the foam thermal conductivity is underestimated, perhaps by a factor of two to three. Increasing the thermal conductivity of the foam would move each of the data points to the left, bringing the predictions and the data into better agreement. The values of $\left(\delta / r_{w}\right)$ for $\phi=0.35$ fall significantly below those for the other liquid volume fractions; foam with liquid volume fractions of the order of 0.35 appears to behave differently from foams with substantially lower liquid volume fractions. (It is possible that a wet soupy foam behaves differently from a very dry foam.) 


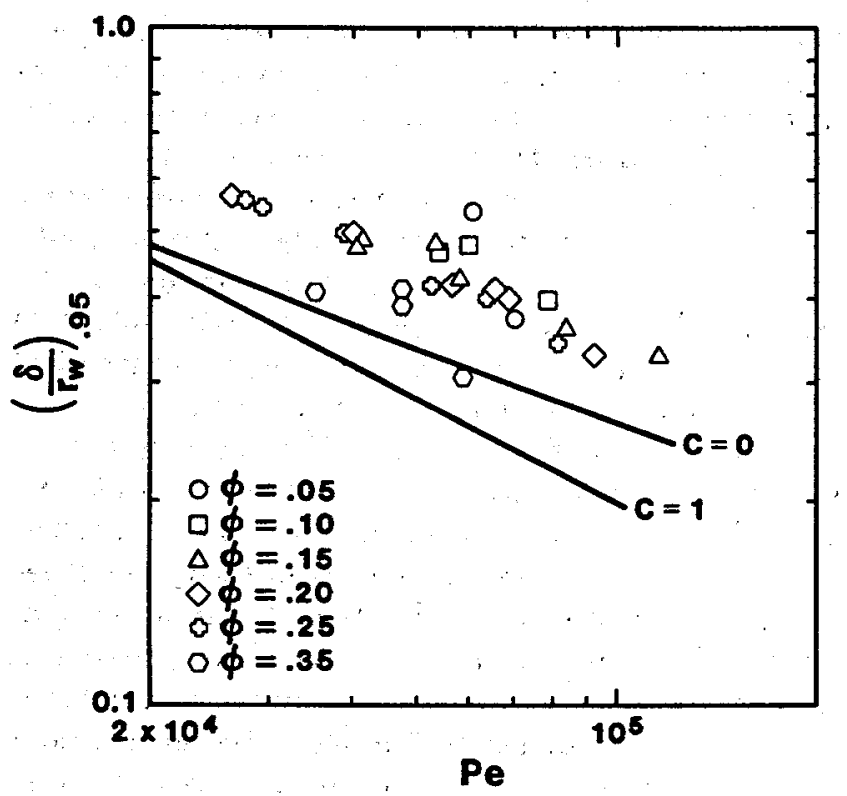

Figure 25. Dependence of Thermal-Boundary-Layer Thickness on Peclet Number

For a fluid with constant properties, local Nusselt numbers can be calculated from the slope at the wall of the experimentally measured temperature profiles. The conventional definition of the Nusselt number for tube flow utilizes the wall-to-bulk-fluid temperature difference:

$\mathrm{Nu}_{\mathrm{x}}=\frac{\mathrm{h}_{\mathrm{x}} \mathrm{D}}{\mathbf{k}}=\frac{\dot{\mathrm{q}}^{\prime \prime}}{\left(\mathrm{T}_{\mathrm{b}}-\mathrm{T}_{\mathrm{w}}\right)} \frac{\mathrm{D}}{\mathrm{k}}=-\frac{2}{\theta_{\mathrm{b}}} \frac{\partial \theta\left(\mathrm{x}^{+}, 1\right)}{\partial \mathbf{r}^{+}}$

In the entry region, the wall-to-inlet (or centerline) temperature difference produces an equally valid definition of the local Nusselt number:

$\tilde{N} u_{x}=\frac{\tilde{h}_{\mathbf{x}} \mathrm{D}}{\mathbf{k}}=\frac{\dot{\mathrm{q}}^{n}}{\left(\mathrm{~T}_{\mathrm{r}}-\mathrm{T}_{\mathrm{w}}\right)} \frac{\mathrm{D}}{\mathrm{k}}=-2 \frac{\partial \theta\left(\mathrm{x}^{+}, 1\right)}{\partial \mathrm{r}^{+}}$.

Knowledge of the bulk temperature depends upon knowledge of the velocity profile; since the velocity profile is not well known, Equation (5-2) is felt to be superior for the present study.

The temperature profiles are nearly linear over a large portion of the boundary layer region. As illustrated by Figure 13, it is believed that the slope in this linear region would extend to the wall at the end of the heated section if the foam is homogenous. Local Nusselt numbers calculated from the definition given by Equation (5-2) are shown in Figure 26. A least-squares linear curve fit to the data in the linear portion of the experimental profiles was used to determine the temperature gradient at the wall. Wall temperatures were estimated from the overall heat-transfer coefficient, and the hot water and the foam temperatures. This calculation will be discussed subsequently in greater detail. These calculated values are compared to the predictions for Bingham plastic fluids with $c=0$ in Figure 26. Although the measurements were taken at $x / r_{w}=239.6$, the local Nusselt numbers are compared to predictions for the location of the end of the heated portion of the test section $\left(x / r_{w}=231.8\right)$. The calculated values form a line that is roughy parallel to the analytical results for a Bingham plastic, once again indicating a more thermally developed flow than predicted. The data for $\phi=0.35$ is substantually different from the data for the other liquid volume fractions, giving further evidence that this wet foam exhibits a different behavior than dry foam with smaller liquid volume fractions.

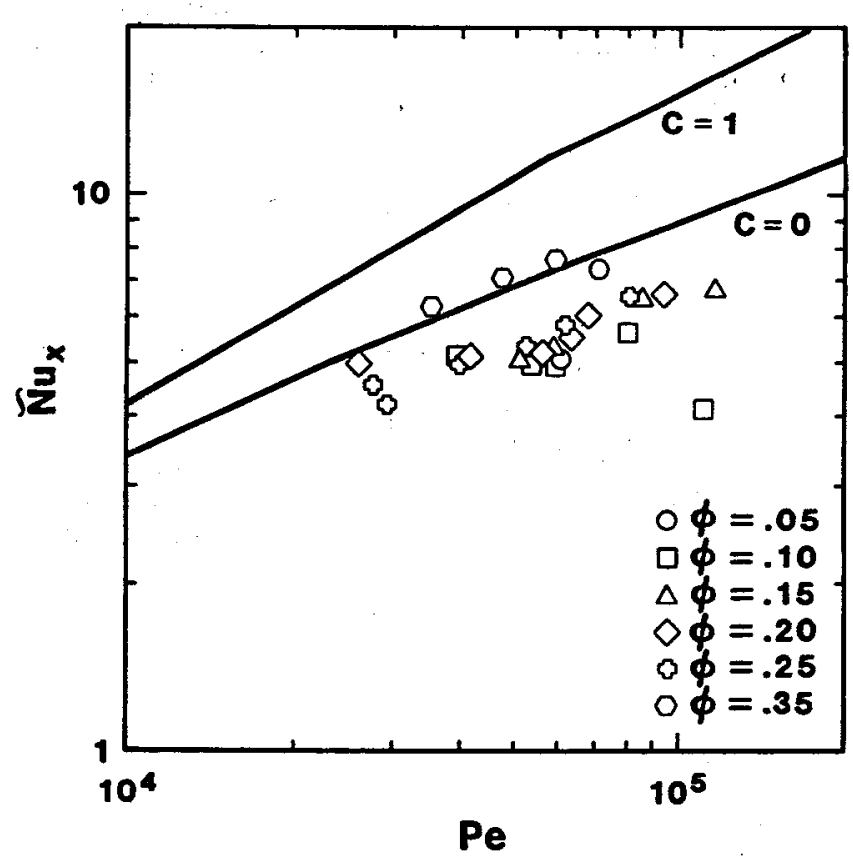

Figure 26. Dependence of Average Nusselt Number on Peclet Number

The heat-transfer coefficient averaged over the test-section length can be determined by performing an energy balance on the test section. Ideally, the heat lost by the hot water (designated hot fluid) is equal to the heat gained by the foam (designated cold fluid). If the test section is idealized as a counterflow heat exchanger, then the effectiveness/NTU relationship as presented by Kays and London ${ }^{8}$ can be written as

$\epsilon=\frac{T_{c_{0}}-T_{c_{i}}}{T_{h_{i}}-T_{c_{i}}}=\frac{1-\exp [-N T U(1-C)]}{1-C \exp [-N T U(1-C)]}$ 
where the subscripts "c" and " $h$ " refer to the cold and hot fluid, respectively; the subscripts " $i$ " and " 0 " refer to inlet and outlet conditions, respectively; NTU is the number of transfer units and is defined by

$\mathrm{NTU}=\frac{(\mathrm{UA})_{2}}{\left(\dot{m}_{\mathrm{p}}\right)_{\mathrm{c}}}$,

where UA is the overall heat-transfer coefficient/area product with the subscript 2 referring to the outer surface of the test section; $\mathbf{m C}_{\mathrm{p}}$ is the capacity rate; and $\mathrm{C}$ is the ratio of cold fluid to hot fluid capacity rates

$\mathrm{C}=\frac{\left(\dot{\mathrm{m}} \mathrm{C}_{\mathrm{p}}\right)_{\mathbf{c}}}{\left(\dot{\mathrm{m}} \mathrm{C}_{\mathrm{p}}\right)_{\mathrm{h}}}$

The overall heat-transfer coefficient is related to the average convective heat-transfer coefficients $\bar{h}_{1}$ and $\bar{h}_{2}$ on the inner and outer test-section surface, respectively, and the thermal resistance of the test section wall through

$$
(\mathrm{UA})_{2}=\frac{1}{\frac{1}{A_{1} \bar{h}_{1}}+\frac{\ln \left(r_{2} / r_{1}\right)}{2 \pi L k_{p}}+\frac{1}{A_{2} \bar{h}_{2}}},
$$

where the subscripts " 1 " and " 2 " refer to inner and outer test-section surface, respectively, $k_{p}$ is thermal conductivity of test-section wall, and $\mathbf{r}$ is pipe radius. $\overline{\mathrm{h}}_{2}$ is determined from turbulent flow in annulus correlations and the experimentally measured hot-water flow rate.

All of the temperatures in Equation (5-3) are bulk-fluid temperatures and for a circular crosssection pipe they can be calculated from a temperature profile as follows:

$\mathrm{T}_{\mathrm{b}} \mathrm{uA}_{\mathrm{c}}=2 \pi \int_{0}^{\mathrm{r}_{\mathrm{w}} \mathrm{T}} \mathrm{T}(\mathrm{r}) \mathrm{u}(\mathrm{r}) \mathrm{rdr}$

In Equation (5-7), $A_{c}$ is the area over which the integration takes place. At the test-section inlet, it is assumed that the temperature is uniform over the cross-section and the temperature in Equation (5-7) can be brought outside the integral sign. In the experimental configuration, $T_{c_{i}}$ is measured by a single RTD located at the centerline of the pipe. The hot-water flow is fully turbulent and should be well mixed as it enters the annulus space surrounding the test section. Consequently, a single temperature measurement will suffice for $T_{h_{i}}$, the inlet hot-water stream is split into two streams and an RTD measures the temperature in each stream individually. The temperature recorded as $T_{h_{i}}$ is the average of the two RTDs. The remaining temperature necessary to calculate the heat exchanger effectiveness is the foam outlet temperature $\mathbf{T}_{\mathrm{c}_{0}}$. Initially, we intended to measure this bulk temperature directly by thermally mixing the foam after it exited from the test section. However, it proved to be very difficult to mix a high viscosity and low thermal diffusivity fluid such as foam. Therefore, we decided to measure the temperature profile directly and perform the integration in Equation (5-7) numerically using an assumed velocity profile. Also, the exitingfoam temperature profile provides additional experimental information not contained in the bulk temperature measurement.

The procedure for determining $\bar{h}_{1}$ can be summarized as follows:

1. Using the experimentally measured temperatures, calculate the effectiveness from Equation (5-3)

2. Using the experimental value for $\mathrm{C}$, [Equation (5-5)], solve (iteratively) Equation (5-3) for NTU

3. Using Equation (5-4), solve for (UA) $)_{2}$

4. Using Equation (5-6), solve for $h_{1}$.

Figure 27 shows the calculated average Nusselt numbers assuming a Bingham-plastic velocity profile and with c determined from the measured wall shear stress, the liquid volume fraction, and the variation of yield stress with liquid volume fraction given in Blackwell and Sobolik. ${ }^{2}$ Once again, a line drawn through the calculated values is roughly parallel to the predictions, but there is a substantial difference between the two, indicating a more thermally developed flow than predicted. 


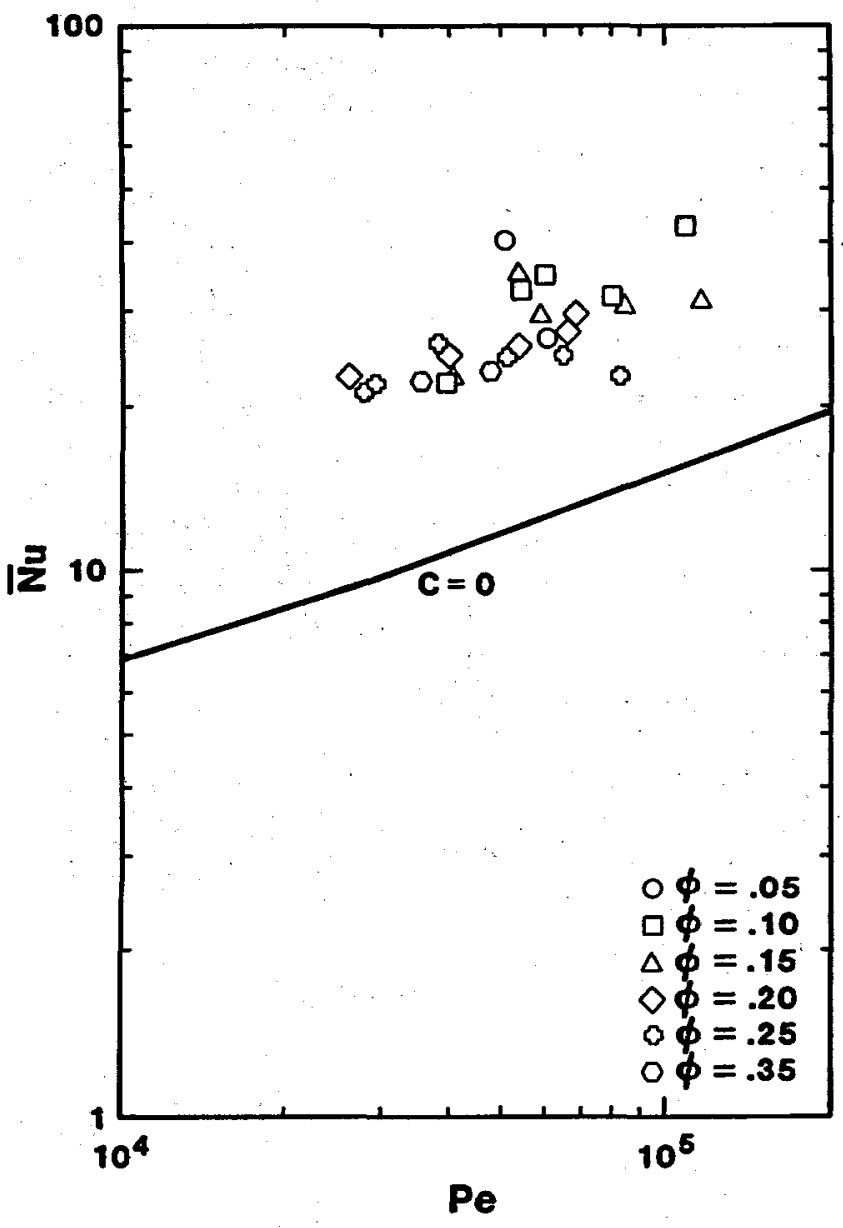

Figure 27. Dependence of Local Nusselt Number on Peclet Number

Figures 28 to 30 present numerical predictions using the Finite-Control-Volume model described in Appendix B and the experimentally measured temperature profile for several different runs. Figure 28 compares prediction and data for Run $30 \mathrm{~A}$, which had a nominal liquid volume fraction of 0.2 . Since the experimentally measured foam inlet temperature was used as an inlet condition for the numerical predictions, the predictions and data are in agreement in the center portion of the pipe. The foam thermal conduc- tivity for the predictions was assumed to be a linear function of liquid volume fraction and gas and liquid conductivities. The general shape of the temperature profile is predicted; however, the experimentally measured thermal-boundary-layer thickness is larger than that predicted. A possible explanation is that the actual thermal conductivity is larger than that calculated from the linear model. The parameters used in the velocity profile for the prediction are given in the figure caption. The predictions did not show a strong sensitivity to small perturbations in the velocity profile.

Figure 29 compares predictions and data for Run 41; the nominal liquid volume fraction is the same as that in Figure 28 but the velocity (and Peclet number) are lower. Again, the general character is predicted but the thermal-boundary-layer thickness is underpredicted. Figure 30 compares predictions with data for a nominal liquid volume fraction of 0.15 with the comparison being similar to that observed in Figures 28 and 29. Since it appears that the foam thermal conductivity is higher than that obtained from the linear model, numerical experiments were performed by increasing the linear conductivity, $k$, by factors of two and three. An arbitrary increase of a factor of two on the thermal conductivity matches the thermalboundary-layer thickness reasonably well. However, the wall temperature is still underpredicted by a considerable amount. In fact, the predicted wall temperature was not very sensitive to the assumed thermal conductivity enhancement factor.

Other computational experiments were performed in an attempt to improve the numerical model; they will be only briefly described. Since the wall temperature was consistently underpredicted, further enhancements of the thermal properties of the foam in the near-wall region were considered. It was postulated that there was a purely liquid film in contact with the pipe wall. By using the thermal properties of the pure liquid phase for material in the wall region, the wall temperature could be increased. However, the thickness of this region was an unknown and the analytical predictions were terminated at this point. 


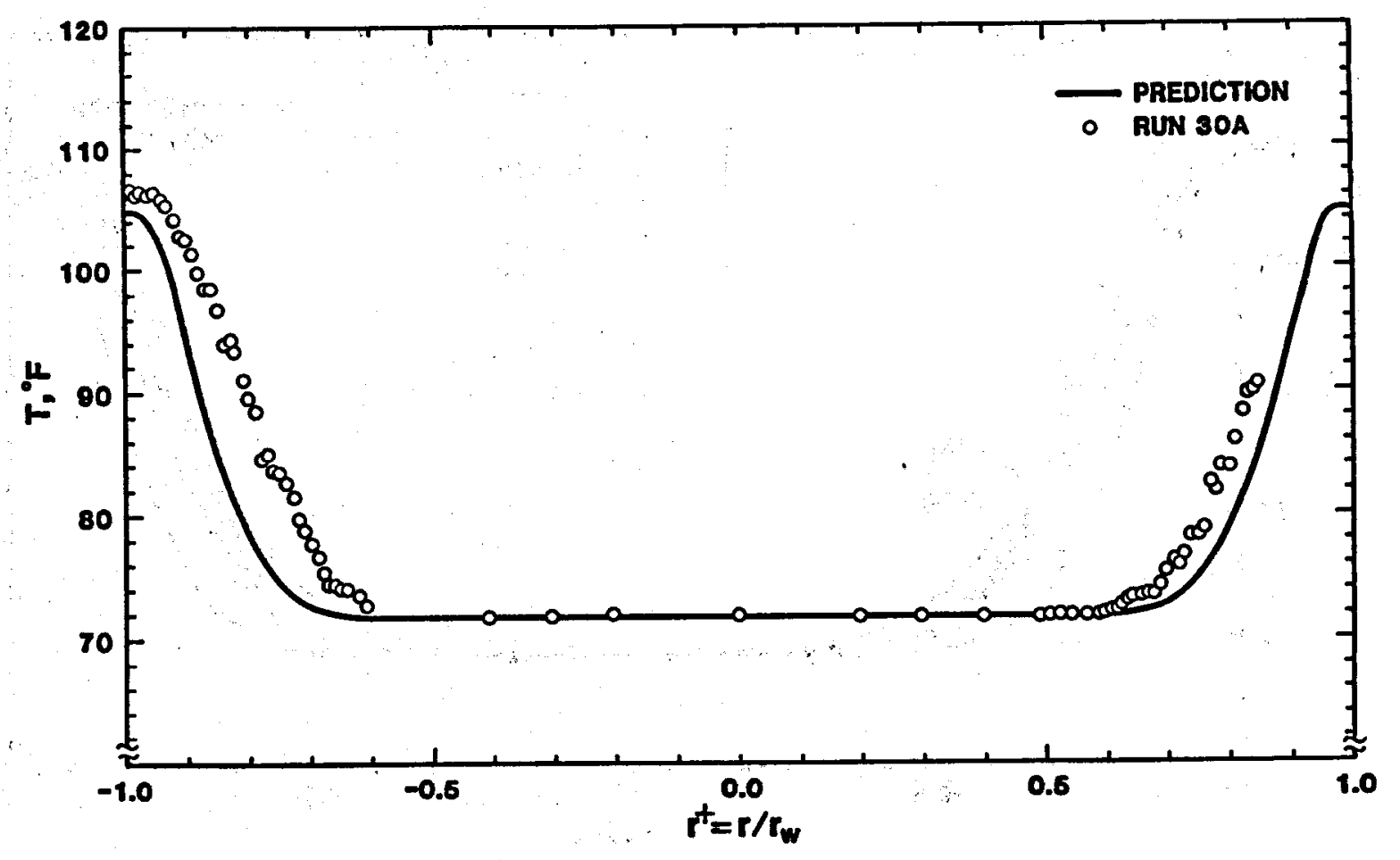

Flgure 28. Predictions and Data for Run 30A $(\alpha=1.85 \mathrm{ft} / \mathrm{s}, \mathrm{c}=0.416, \mathrm{~m}=1, \phi=0.203)$

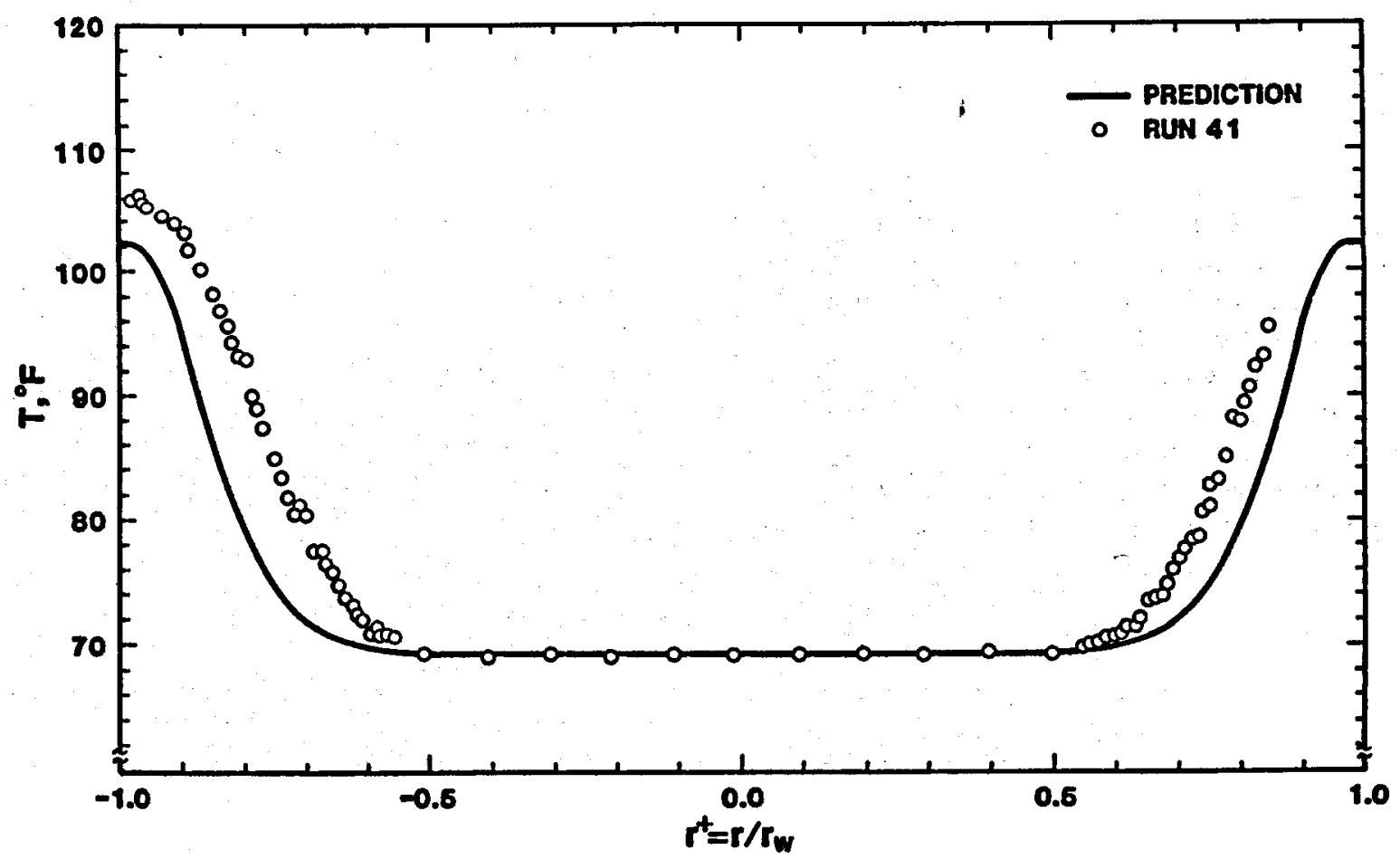

Figure 29. Predictions and Data for Run $41(\mathrm{u}=1.41 \mathrm{ft} / \mathrm{s}, \mathrm{c}=0.114, \mathrm{~m}=1, \phi=0.193)$ 


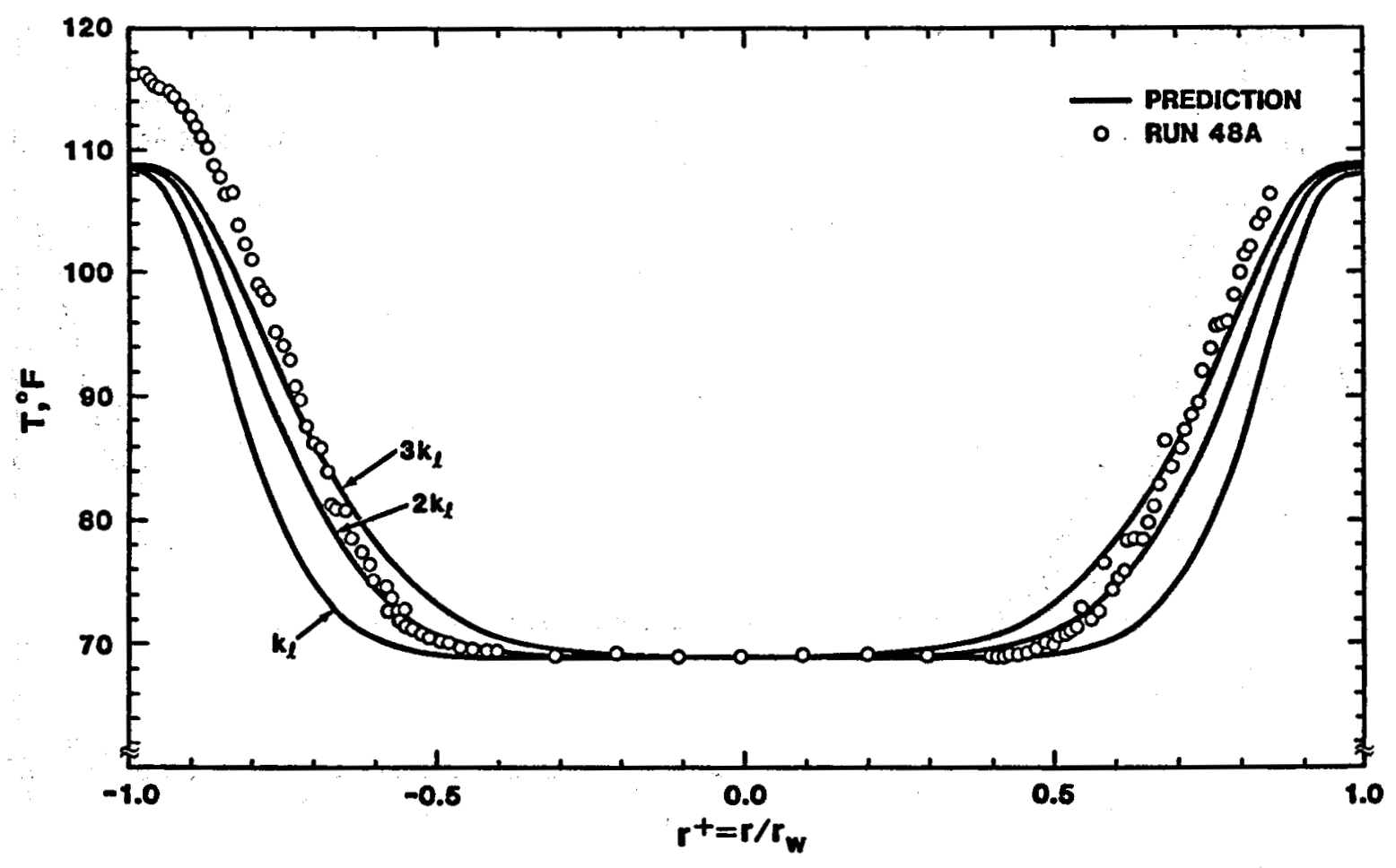

Figure 30. Predictions and Data for Run 48A $(\overline{\mathrm{U}}=0.94 \mathrm{ft} / \mathrm{s}, \mathrm{c}=0.125, \phi=0.145)$ 


\section{Summary and Conclusions}

Photographs of both static and flowing foam samples have been taken. It appears that the existence of an axial pressure gradient causes changes in the structure of the foam. Consequently, theories developed from ideas about how foams behave in a static environment may not be applicable to flowing foams: The structure of foam also changes in the vicinity of a solid boundary; this implies that even with a uniform cell size, one would expect a different behavior in the vicinity of a wall.

Experimental measurements of velocity and tem. perature profiles of aqueous foams in tube flow have been measured using hot-film and thermocouple probes, respectively. The velocity profiles confirm the existence of a plug-flow region near the pipe centerline where the local shear stress is below the yield stress. The hot-film probe was calibrated by assuming an analytical relationship between the local mass flux and the anemometer output voltage. The calibration constants were then chosen such that the integral of the velocity profile matches the experimentally measured mass flux. This calibration approach was indirect in that velocity was not measured directly by some independent means, and was not entirely satisfactory. A calibration procedure that measured velocity directly would have been preferable.

The temperature profile measurements confirmed the existence of a developing thermal boundary layer. Since the Peclet number is large $(10,000$ to 100,000$)$, the entire 3-m test section was in the thermal entrance region. Aqueous foams are a poor heat-transfer medium because of their low thermal diffusivity. As the Peclet number increases, the thermal-boundarylayer thickness at the end of the test section decreases.
A numerical technique was developed to solve the energy equation for both the foam and the surrounding solid regions. The velocity profile was required as input. Although the numerical model predicts the general features of the temperature-profile development, close agreement between predictions and data was not obtained. Part of the discrepancy may be due to the lack of experimental data on the thermal conductivity of flowing foams. The only experimental data for foam thermal conductivity used a static foam sample; there is reason to suspect that the thermal conductivity of flowing foams is considerably higher (two to three times) than that for static-foam samples. The lack of agreement between theory and experiment suggests that it is not possible to model the two-phase foam as a single-phase fluid.

A practical implication of the low thermal diffusivity of aqueous foams is that, for a geothermal drilling application, there will be a significant temperature difference across the wellbore annulus. Consequently, the foam adjacent to the outer annulus surface will experience temperatures close to the local formation temperature. It is conceivable that the foam adjacent to the outer annulus surface will lose its lifting capacity because of the high temperatures to which it is exposed. Very little information is known about the degradation of foam lifting capacity with elevated temperature.

The body of knowledge of the hydrodynamic and heat-transfer behavior of aqueous foams has been considerably enhanced by this report and its companion (Reference 2). However, there is a tremendous amount of work left to be done before aqueous foams are as well understood and characterized as air and water, the two primary ingredients of foam. 


\section{References} 1973).

'J. J. Bikerman, Foams (New York: Springer-Verlag,

${ }^{2}$ B. F. Blackwell and K. B. Sobolik, An Experimental Investigation of Pressure Drop of Aqueous Foam in Laminar Tube Flow, SAND85-1921 (Albuquerque, NM: Sandia National Laboratories, to be published).

${ }^{3}$ R. B. Bird, R. C. Armstrong, and O. Hassager, Dynamics of Polymeric Liquids-Fluid Mechanics, Vol. 1 (New York: John Wiley \& Sons, 1977).

'B. F. Blackwell, Numerical Results for the Solution of the Graetz Problem for a Bingham Plastic in Laminar Tube Flow with Constant Wall Temperature, SAND84-0956 (Albuquerque, NM: Sandia National Laboratories, August 1984).
${ }^{5}$ B. F. Blackwell, "Numerical Solution of the Graetz Problem for a Bingham Plastic in Laminar Tube Flow with Constant Wall Temperature," ASME J. of Heat Transfer 107(2):466-468 (May 1985).

P. B. Bailey, SLEIGN, An Eigenvalue-Eigenfunction Code for Sturm-Louiville Problems, SAND77-2044 (Albuquerque, NM: Sandia National Laboratories, January 1978).

7D. B. Spalding, "A Novel Finite-Difference Formulation for Differential Expressions Involving Both First and Second Derivatives," Int. J. Num. Methods Eng. 4:551.

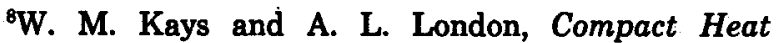
Exchangers, 2nd ed. (New York: McGraw-Hill Book Company, 1964). 


\section{APPENDIX A}

\section{Description of the Experimental Apparatus}

A schematic of the experimental apparatus is shown in Figure A-1. The test section is basically a counterflow heat exchanger consisting of a $3.00-\mathrm{m}$ (9.84-ft) long by $2.588-\mathrm{cm}$ (1.019-in.) ID Type 304 stainless-steel tube with a wall thickness of $0.6033-\mathrm{cm}$ $(0.2375-\mathrm{in}$.) that is concentric within a $5.458-\mathrm{cm}$ ID steel (nominal 2 in. IPS schedule 20) pipe. For heattransfer measurements, hot water flows upward through the resulting $1.664-\mathrm{cm}(0.655$-in.) annulus; for velocity-profile measurements, the hot water loop is inactive. Foam flows vertically downward through the inner tube.

The hot water loop consists of a $15-\mathrm{kw}$ electric heater and adjustable power supply, two centrifugal circulation pumps in series, and a turbine flow meter. Water temperature is controlled by varying the amount of electrical power supplied to the heater. Type $\mathrm{K}$ thermocouples are used to measure the tem- perature at the inlet and the outlet of the heater. The hot water volumetric flow rate is typically about $0.5 \mathrm{l} / \mathrm{s}(8 \mathrm{gpm})$. The hot water enters the annulus at a right angle to the test section through two pipes that are 180 degrees apart; the outlet has a similar configuration. One individually calibrated (resistance temperature device) RTD in each of the inlets and outlets of the test-section annulus are used to measure the hot water temperatures, which are typically around $50^{\circ} \mathrm{C}$ $\left(120^{\circ} \mathrm{F}\right)$ for heat-transfer tests. The variation in indicated temperature for both the two inlet and two outlet RTDs was within the measurement accuracy capability of $0.14^{\circ} \mathrm{C}\left(0.25^{\circ} \mathrm{F}\right)$. For velocity-profile measurements, water in the annulus was at room temperature and was not circulated. Due to the large hot-water flow rate, the temperature drop for the hot water along the test section is typically less than $1^{\circ} \mathrm{C}$ $\left(2^{\circ} \mathrm{F}\right)$.

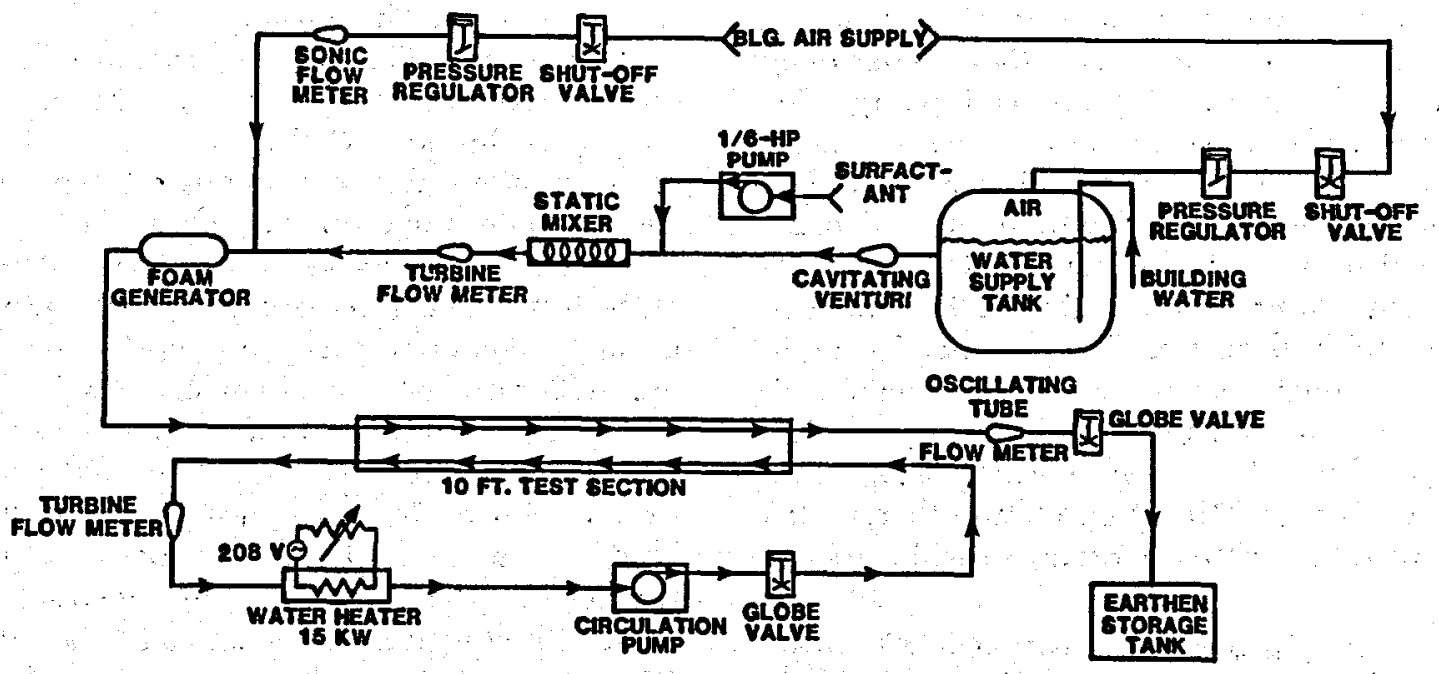

Figure A-1. Schematic of Experimental Apparatus 
Five thermocouples* mounted on the outside of the inner tube provide a measurement of the testsection outer wall temperature. The first of these thermocouples is located $0.3 \mathrm{~m}(1 \mathrm{ft})$ from the testsection inlet; the others are located at $0.6-\mathrm{m}(2-\mathrm{ft})$ intervals. Due to the capacity rates of the foam and the hot water, the boundary condition for the foam was nearly isothermal; the wall thermocouples were uniform to within $1.7^{\circ} \mathrm{C}\left(3^{\circ} \mathrm{F}\right)$ for the heat-transfer tests.

Air is combined with a water/surfactant mixture in the correct proportions to produce foam with the desired liquid volume fraction. Air is drawn from the large building supply tanks, which are maintained at 6.9 bars ( $100 \mathrm{psi})$. The mass flow rate is determined by the combination of a sonic flow nozzle and an upstream pressure regulator. Provided the flow is sonic at the nozzle throat, the mass flow rate of the air is held constant regardless of downstream pressure fluctuations. A series of nozzles manufactured by FlowDyne Engineering, Inc., with diameters ranging from $0.343 \mathrm{~mm}$ to $1.40 \mathrm{~mm}(0.0135$ in. to $0.055 \mathrm{in}$.) provide for a range of mass flow rates. The stagnation temperature of the air flow is measured with a Type $K$ thermocouple located upstream of the nozzle.

Water is drawn from a $570-\ell$ (150-gal) tank that is pressurized to a maximum of 6.9 bars (100 psi) with building air. The water volumetric flow rate is controlled with a cavitating venturi (Fox Valve Development Corporation); due to the constant upstream pressure, the cavitating venturi provides a constant flow rate similar to the sonic nozzle on the gas side.** Surfactant is supplied from a $200-\ell$ (55-gal) barrel by a variable-stroke positive-displacement pump. The pump has two adjustable stroke heads with a maximum capacity of $3.5 \mathrm{~m} \ell / \mathrm{s}(3.4 \mathrm{gph})$ per head. The volumetric flow rate of surfactant is always maintained at 0.01 of the water volumetric flow rate. The water and surfactant pass through a TAH Industries static mixer to blend the two constituents. The liquid flow passes through one of two turbine meters in parallel. These meters are manufactured by Flow Technologies, Inc. The larger capacity meter has a range of 0 to $0.158 \mathrm{\ell} / \mathrm{s}(0$ to $2.5 \mathrm{gpm})$; the other, with a range of 0 to $0.0315 \ell / \mathrm{s}$ ( 0 to $0.5 \mathrm{gpm}$ ), provides greater

\footnotetext{
*These thermocouples were components of RdF Corporation microfoil heat-flow sensors, Model \#P/N20457-1. Calibration of these sensors for turbulent flow of air through the test section was found to be dependent upon the flow rate of hot water in the annulus. Consequently, a calibration that would be valid for foam flow was not possible.

**Early attempts at producing a steady flow using a variable-stroke metering pump and a pulsation dampener were not successful.
}

accuracy at lower flow rates. The range of liquid flow rates for the experiments reported is 0.00315 to 0.0632 $\ell / \mathrm{s}(0.05$ to $1.00 \mathrm{gpm})$. The addition of $1 \%$ by weight surfactant to the water was not deemed sufficient to alter the turbine meter calibration.

The gas and liquid flows are mixed immediately upstream of the foam generator. Experience suggests that vertically upward foam flow with the air injected at the bottom of the foam generator and the liquid injected horizontally will produce foam of acceptable quality. Steel wool was placed in the air line prior to the point at which the air is injected into the liquid flow in an attempt to provide a uniform pressure at this point. The foam generator is a packed bed of copper wool in a vertical circular tube with an ID of $3.468 \mathrm{~cm}\left(1.365 \mathrm{in}\right.$.). The packing density is $0.56 \mathrm{~g} / \mathrm{cm}^{3}$ ( $\left.34.7 \mathrm{lb}_{\mathrm{m}} / \mathrm{ft}^{3}\right)$; the packing length is $11.43 \mathrm{~cm}$ (4.5 in.).

After leaving the generator, the foam enters the test section. The test section is mounted vertically in a $22-\mathrm{cm}$ by $23-\mathrm{cm}(8-i n$. $\times 8.5$-in.) cross-section by 1.9 cm (0.75-in.) thick wood box. The vertical orientation of the test section helps prevent foam drainage problems; the foam flows downward through the test section. The cavity between the test section and the box is filled with silica aerogel insulation, which is available from W. R. Grace and Co., Davison Chemical Division.

The foam inlet and outlet to the test section are connected to nylon bushings that seal the annulus space from the center pipe; the foam flows through a hole in the bushing, which has the same diameter as the test section. The bushings are held via a flexible bracket to the adjoining pieces that are threaded into the bracket. The outlet is connected to a chlorinated poly vinyl chloride (CPVC) adapter which holds the probe used for measuring temperature profiles. For a description of the probe assembly, see Appendix C.

The pressure change over an 2.4-m (8.0-ft) length of the test section is measured with a Validyne Corporation variable-reluctance differential pressure transducer. Two transducers are available with ranges of 0 to 0.0862 bars ( 0 to 1.25 psid) and 0 to 0.22 bars ( 0 to 3.2 psid). A 0 to 6.89 bars (0 to 100 psid) Gould Corporation differential pressure transducer and a barometer are used to measure the static pressure at the center of the test section. All pressure transducers were calibrated at Sandia National Laboratories. The 1.59-mm (0.0625-in.) diameter stainless-steel tubes used for pressure ports penetrate the outer pipe and are held in place with Conax gland nuts. The connection with the inner tube is sealed with an 0 -ring at the bottom of a counterbored hole. The details of the pressure port are shown in Figure A-2. The pressure port has a diameter of $1.0 \mathrm{~mm}(0.040 \mathrm{in}$.). 


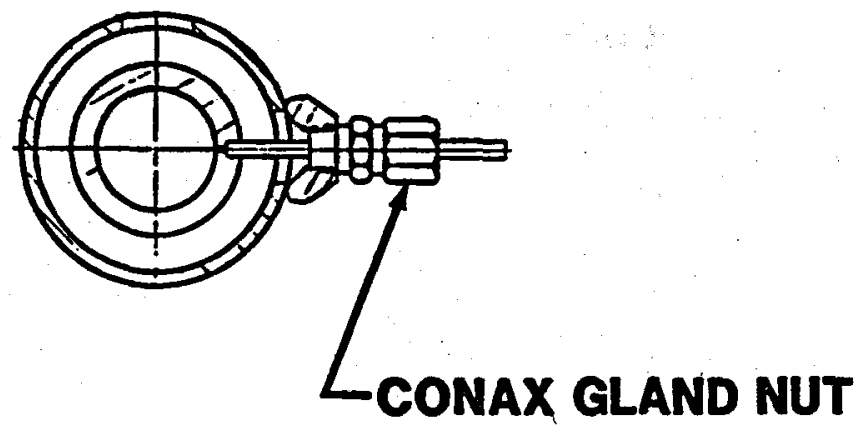

Figure A-2. Details of the Pressure Port

Due to the long lines between the pressure ports and the differential pressure transducers, foam tends to backup into the lines, thereby producing erroneous readings. An elaborate valving scheme was designed to flush foam from the pressure lines immediately before taking measurements. The schematic of the valving arrangement is shown in Figure A-3. Valves 2, 4, and 6 are three-way on/off valves. In one position, the lines are connected to the building air supply via a pressure regulator; in the other open position, the lines are connected to the pressure transducers. Valves 1,3 , and 5 seal off the test section during a temperature-profile measurement. Valve 7 protects the low-range pressure transducer from being over-ranged.
Individually calibrated RTDs are used to measure the foam temperature at the inlet and outlet to the test section (one each). Type $\mathrm{K}$ thermocouples are used to measure various temperatures, such as the ambient temperature, the temperature of the water flow to the foam, and the temperature inside the insulation in the wood box. All thermocouples besides the temperature probe and the ones on the wall of the test section are referenced to an electronic reference junction maintained at $65^{\circ} \mathrm{C}\left(150^{\circ} \mathrm{F}\right)$; other thermocouples used an ice bath as a reference junction.

An HP 1000 series computer is used for all data acquisition except the temperature-profile measurements. Pressure readings are averaged over approximately 15 scans taken during a 1 to 1.5 -min interval. The remaining measurements (excluding temperature profile) are scanned during the three pressuremeasurement intervals and are, therefore, averaged over approximately 45 scans. (The pressures upstream and downstream of the sonic nozzle and the static test-section pressure are measured with the same transducer.) Temperature profiles were acquired with an HP 85 desktop computer along with an HP 3497 data acquisition system. Temperature-profile measurements were typically averaged over 200 scans taken over approximately $15 \mathrm{~s}$. A typical temperature profile consisted of 90 radial positions and would require $\mathbf{4 0 ~} \mathrm{min}$ to acquire the data.

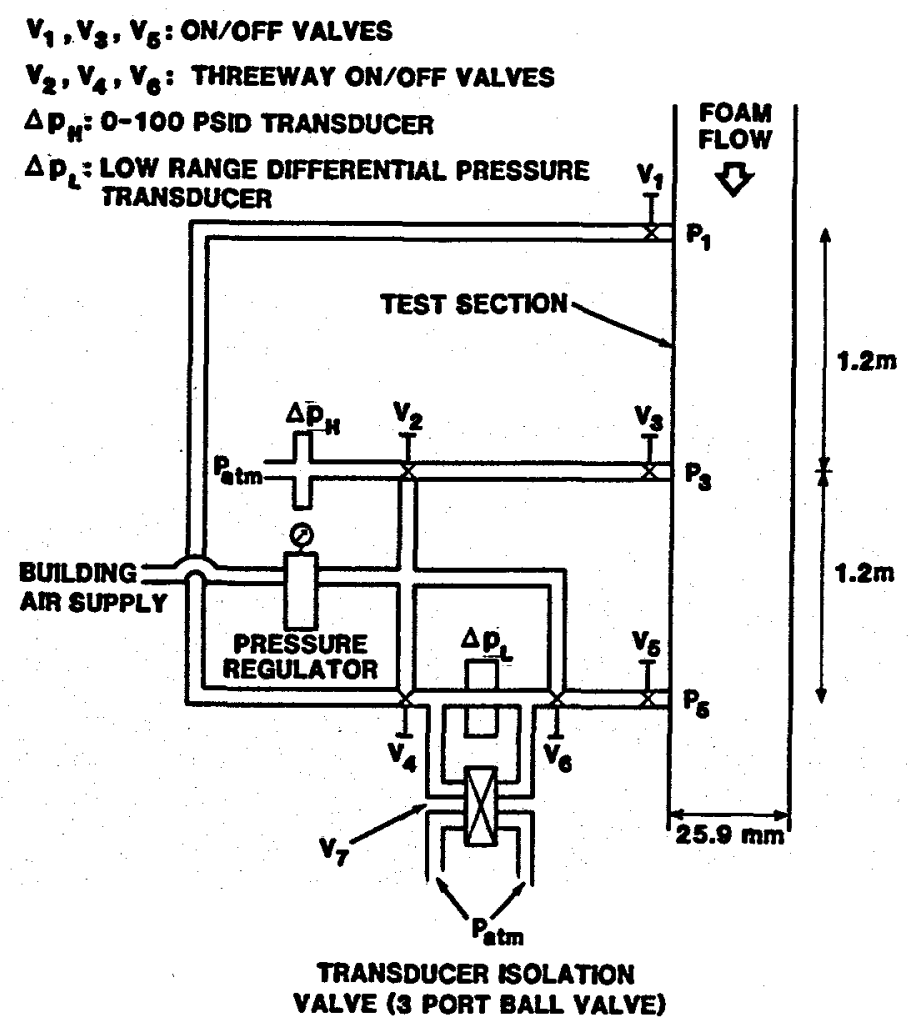

Figure A-3. Schematic of Valving Arrangement 



\section{Development of Finite-Control-Volume Model for Experimental Test Section}

For the experimental configuration of this study, it was desired to develop a numerical model that would predict the experimental temperature profiles. This model had to be capable of considering the conduction/convection within the foam as well as conduction within the pipe walls. A schematic of the region modeled is shown in Figure B-1. Within the foam, it was assumed that the velocity profile was fully developed and known. Consequently, only the energy equation was solved.

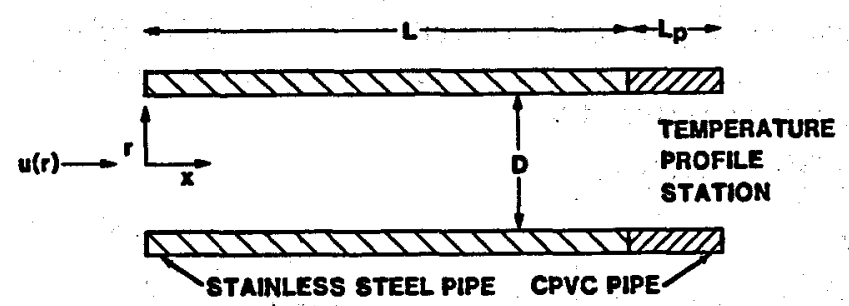

Figure B-1. Region of Test Section for Which Numerical Model was Constructed

$\rho C_{p}\left(\frac{\partial T}{\partial t}+u \frac{\partial T}{\partial x}\right)=k\left[\frac{1}{r} \frac{\partial}{\partial r}\left(r \frac{\partial T}{\partial r}\right)+\frac{\partial^{2} T}{\partial x^{2}}\right]-r \frac{\partial u}{\partial r}$

Although the foam energy equation considers axial conduction, viscous dissipation, and energy storage, these terms are likely to be relatively unimportant for the conditions of this study. Within the pipe walls, the energy equation is

$\rho C_{p} \frac{\partial T}{\partial t}=k\left[\frac{1}{r} \frac{\partial}{\partial r}\left(r \frac{\partial T}{\partial r}\right)+\frac{\partial^{2} T}{\partial x^{2}}\right]$.

Equations (B-1) and (B-2) are solved numerically using the Finite-Control-Volume procedure; this procedure combines some of the features of finitedifference/energy-balance methods with the element ideas of the Finite-Element methods. An energy balance over a finite control volume will be performed using the integral form of Equations (B-1) and (B-2).

The region of interest presented in Figure B-1 will be divided into rectangular elements. Although the regular geometry of this problem is well suited to rectangular elements, the Finite-Control-Volume method can be used with both arbitrary triangular and quadrilateral elements. A typical rectangular element is shown in Figure B-2. The local velocity along the $i-j$ boundary is $u_{S}$ and the local velocity along the $k-\ell$ boundary is $u_{N^{*}}$. The control-volume boundaries are drawn at an axial (x) position corresponding to the axial midpoint and at a radial position given by the root-mean-square radius. Consequently, the four quadrants of each element that are defined by the control-volume boundaries have equal volumes and equal areas normal to the axial-flow direction.

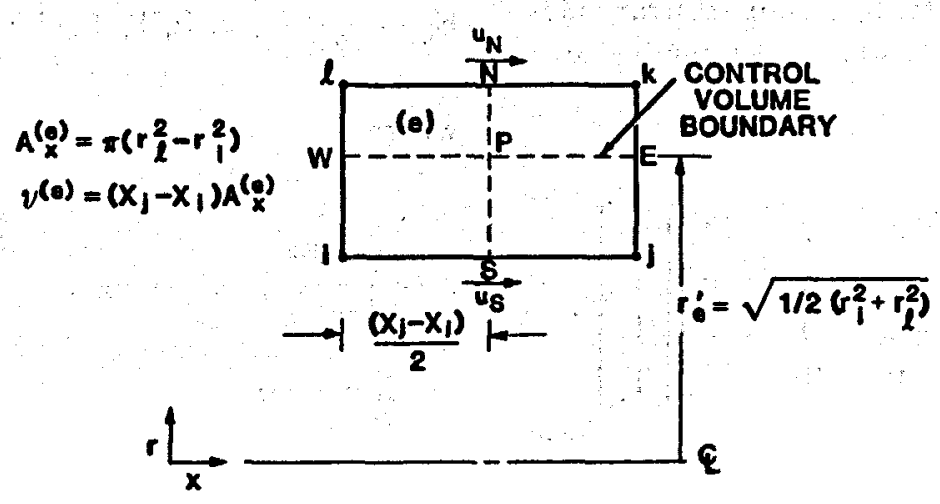

Figure B-2. Schematic of General Rectangular Element "e" 
Heat flow, energy flow, and energy storage matrices will now be defined on an element basis. First, consider conduction in the radial direction. For steady radial conduction without sources, the temperature profile is logarithmic in the radial coordinate. Hence, the radial heat flow by conduction at the controlvolume boundary W-P in Figure B-2 can be written as

$Q_{i_{i}}=2 \pi \frac{\left(x_{j}-x_{i}\right)}{2} k \frac{\left(T_{i}-T_{\ell}\right)}{\ln \left(r_{\ell} / r_{i}\right)}$

This result can be generalized to define the element radial conduction matrix as follows:

Radial Conduction $\left(r_{i} \neq 0\right)$

$\left[\begin{array}{l}Q_{i} \\ Q_{j} \\ Q_{k} \\ Q_{l}\end{array}\right]^{(0)}=\frac{\pi(k \Delta x)^{(e)}}{\ln \left(r_{l} / r_{i}\right)}\left[\begin{array}{rrrr}1 & 0 & 0 & -1 \\ 0 & 1 & -1 & 0 \\ 0 & -1 & 1 & 0 \\ -1 & 0 & 0 & 1\end{array}\right]\left[\begin{array}{c}\mathrm{T}_{\mathrm{i}} \\ \mathrm{T}_{\mathrm{j}} \\ \mathrm{T}_{\mathbf{k}} \\ \mathrm{T}_{\ell}\end{array}\right]$

The superscript (e) denotes an element property or characteristic. Note that the element radial conduction matrix is symmetrical; this is because

$Q_{i_{r}}^{(e)}=-Q_{\ell_{r}}^{(e)}$

and

$\mathbf{Q}_{\mathbf{j}_{\mathbf{z}}}^{(\boldsymbol{e})}=-\mathbf{Q}_{\mathbf{q}}^{(e)}$

When the element boundary is part of an axis of symmetry, then Equation (B-4) is not valid because $r_{i}=0$. For this case, it will be assumed that the temperature profile is linear in $\mathbf{r}$ and the radial heat-flow equation analogous to Equation B-3 is

$Q_{i}=2 \pi \frac{r_{\ell}}{\sqrt{2}} \frac{\Delta x}{2} k \frac{\left(T_{i}-T_{\ell}\right)}{r_{\ell}}$

Generalizing Equation (B-5) for an arbitrary element " $e$ " that lies along the axis of symmetry, one obtains

Radial Conduction $\left(r_{i}=0\right)$

$\left[\begin{array}{l}Q_{i} \\ Q_{j} \\ Q_{k} \\ Q_{\ell}\end{array}\right]^{(\theta)}=\frac{(k \Delta x)^{(0)}}{\sqrt{2}} \pi\left[\begin{array}{rrrr}1 & 0 & 0 & -1 \\ 0 & 1 & -1 & 0 \\ 0 & -1 & 1 & 0 \\ -1 & 0 & 0 & 1\end{array}\right]\left[\begin{array}{c}T_{i} \\ T_{j} \\ T_{k} \\ T_{\ell}\end{array}\right]$.
The expressions for axial conduction and convection will be obtained using the exponential scheme of Spalding. ${ }^{1,2}$ The axial conduction crossing controlvolume-boundary P-S in Figure B-2 is

$Q_{i}=k \frac{A_{z}^{(e)}}{2} f_{s} \frac{\left(T_{i}-T_{j}\right)}{\Delta x}$

where $A_{z}^{(e)}$ is the control volume area normal to the direction of heat flow and is defined by

$A_{\mathbf{z}}^{(e)}=\pi\left(r_{\ell}^{2}-r_{i}^{2}\right)$,

and $f_{a}$ is the exponential differencing factor

$f=\frac{P e^{P / 2}}{e^{P}-1}, \quad \lim _{P \rightarrow 0} f=1.0 \quad: \quad \lim _{P \rightarrow \infty} f=0$

where $\mathbf{P}$ is the grid-scale Peclet number

$P=\frac{u \Delta x}{\alpha}$.

Note that $\mathbf{P}=0$ corresponds to conduction only; for this case, Equation (B-7) is effectively a central difference at the control-volume interface. Equation (B-7) can be generalized to

Axial Conduction

$\left[\begin{array}{l}Q_{i} \\ Q_{j} \\ Q_{k} \\ Q_{\ell}\end{array}\right]^{(0)}=\frac{1}{2}\left(\frac{k A_{z}}{\Delta x}\right)^{(0)}\left[\begin{array}{rrrr}f_{S} & -f_{S} & 0 & 0 \\ -f_{S} & f_{S} & 0 & 0 \\ 0 & 0 & f_{N} & -f_{N} \\ 0 & 0 & -f_{N} & f_{N}\end{array}\right]^{(0)}\left[\begin{array}{l}T_{i} \\ T_{j} \\ T_{k} \\ T_{\ell}\end{array}\right]$.

(B-11)

Note that $f_{N}$ and $f_{S}$ are calculated using $u_{N}$ and $u_{S}$, respectively.

The axial convection crossing control-volumeboundary P-S in Figure B-2 is

$\mathrm{E}_{\mathrm{i}_{2}}=\frac{\mathrm{A}_{\mathrm{z}}^{(e)}}{2}(\rho \mathrm{c}) \mathrm{u}_{\mathrm{s}}\left(\mathrm{g}^{\prime} \mathrm{T}_{\mathrm{i}}+g^{\prime} \mathrm{T}_{\mathrm{j}}\right)$

where

$$
\begin{gathered}
g=\frac{1-e^{P / 2}}{1-e^{P}}, g^{\prime}=1-g, \quad \lim _{P \rightarrow 0} g=\frac{1}{2} \\
\lim _{P \rightarrow \infty} g=0
\end{gathered},
$$


As the grid-scale Peclet number becomes large, Equation (B-12) reduces to upwind differencing; at $P=0$, it becomes a central difference. Equation (B-12) can be generalized to

\section{Axial Convection}

$\left[\begin{array}{l}E_{i} \\ E_{j} \\ E_{k} \\ E_{\ell}\end{array}\right]_{x}^{(o)}=\frac{1}{2}\left(A_{x} \rho c\right)^{(\theta)}$

$\cdot\left[\begin{array}{rrrr}u_{S} g_{S}^{\prime} & u_{S} g_{S} & 0 & 0 \\ -u_{S} g_{S}^{\prime} & -u_{S} g_{s} & 0 & 0 \\ 0 & 0 & -u_{N} g_{N} & -u_{N} g_{N}^{\prime} \\ 0 & 0 & u_{N} g_{N} & u_{N} g_{N}^{\prime}\end{array}\right]^{(0)}\left[\begin{array}{c}T_{i} \\ T_{j} \\ T_{k} \\ T_{l}\end{array}\right]$.

The sign convention for the various energy/heat-flow terms is given in Figure B-3.

The energy contribution due to viscous dissipation was determined by integrating $\tau \frac{\partial u}{\partial r}$ over each of the four element quadrants. For example,

$u^{\prime \prime \prime}=-\frac{\Delta x}{2} \int_{a}^{b} \tau \frac{\partial u}{\partial r} 2 \pi r d r$

where the limits of the integral will be specified subsequently. The work reported here considered the Bulkley-Herschel fluid, which is a combination of the power law and Bingham plastic:

$\tau=\tau_{y}-\eta\left(\frac{r_{w}}{u} \frac{\partial u}{\partial r}\right)^{n-1} \frac{\partial u}{\partial r}$.

The velocity profile for the Bulkley-Herschel fluid is given by

$$
u^{+}=\frac{u}{\mathrm{a}}= \begin{cases}\frac{1-\left(\frac{r^{+}-c}{1-c}\right)^{m+1}}{1-2 \frac{(1-c)}{(m+2)}+\frac{2(1-c)^{2}}{(m+2)(m+3)}}, & r^{+} \geq c \\ \frac{1}{1-2 \frac{(1-c)}{(m+2)}+\frac{2(1-c)^{2}}{(m+2)(m+3)}}, & r^{+} \leq c\end{cases}
$$

where $m=1 / n$.

The viscous dissipation per-unit-volume can be written as

$$
-\tau \frac{\partial \mathrm{u}}{\partial \mathrm{r}}=-\eta\left(\frac{\overline{\mathrm{u}}}{\mathrm{r}_{\mathrm{w}}}\right)^{2}\left[\frac{\tau_{\mathrm{y}} \mathrm{r}_{\mathrm{w}}}{\eta \overline{\mathrm{u}}}+\left(-\frac{\partial \mathrm{u}^{+}}{\partial \mathrm{r}^{+}}\right)^{\mathrm{n}}\right] \frac{\partial \mathrm{u}^{+}}{\partial \mathrm{r}^{+}} .
$$

The evaluation of the integral will depend on the location of the element relative to the line $\mathrm{r}^{+}=c$. For example, if the element lies wholly within the plugflow region of Equation (17), then the velocity gradient (and hence the viscous dissipation) is identically zero. These four possible conditions are identified as follows:

1) $\mathbf{r}^{+}=\mathrm{c}$ lies below the bottom of element $\left(\mathrm{r}_{\mathrm{i}}^{+}>\mathrm{c}\right)$

2) $\mathbf{r}^{+}=c$ lies in bottom portion of element $\left(r_{i}^{+} \leq c \leq r_{e}^{+}\right)$

3) $\mathbf{r}^{+}=\mathrm{c}$ lies in top portion of element $\left(\mathbf{r}_{\mathrm{e}}^{+} \leq \mathrm{c} \leq \mathrm{r}_{\ell}^{+}\right)$

4) $\mathbf{r}^{+}=\mathbf{c}$ lies above the top of element $\left(\mathbf{r}_{\ell}^{+}<\mathrm{c}\right)$.

These four conditions are also shown in Figure B-4.

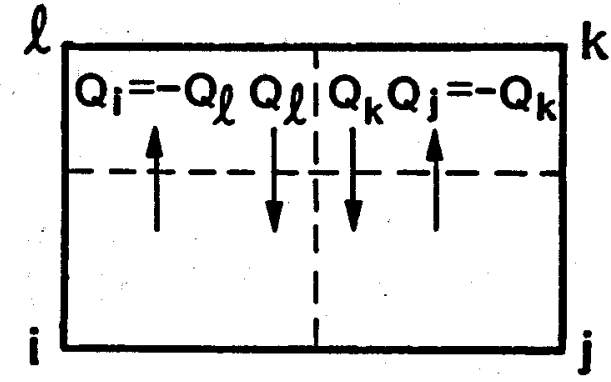

a) RADIAL CONDUCTION

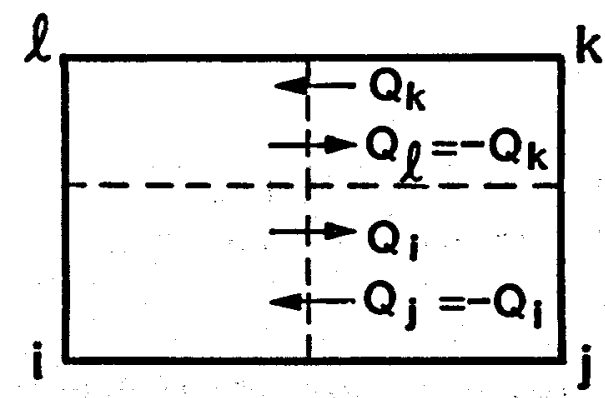

b) AXIAL CONDUCTION

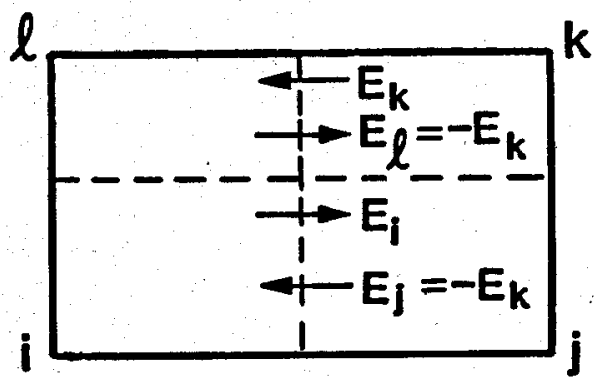

c) AXIAL CONVECTION

Figure B-3. Schematic of Heat and Energy Flow Terms Within an Element 


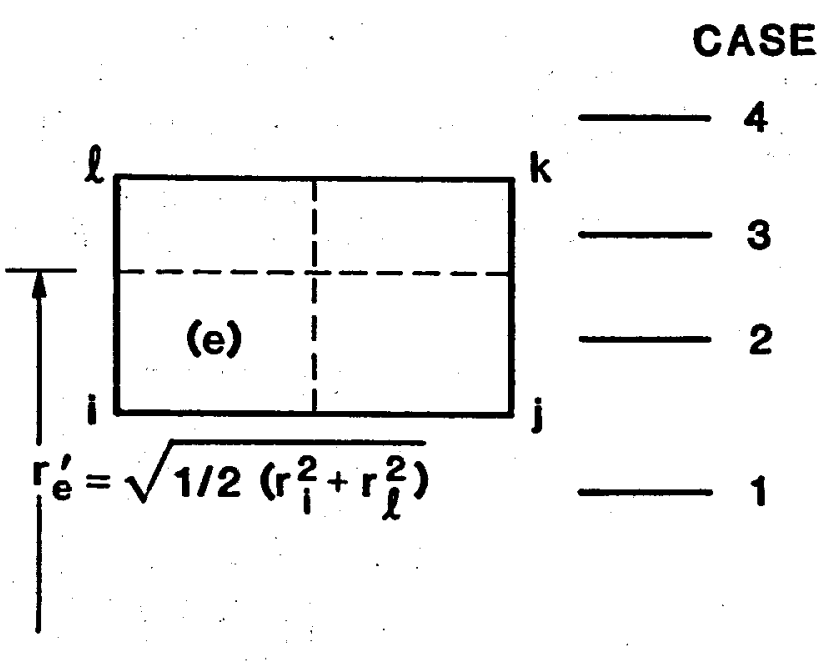

Figure B-4. Identification of Four Regions for Evaluation of Viscous Dissipation Terms

Using Equations (17) and (18) in Equation (15), the element-viscous-dissipation term can be written as

$$
\begin{aligned}
U=\eta \mathbf{u}^{2} \pi \Delta x & \left.\frac{\mathrm{m}+1}{(1-c)\left[1-\frac{2(1-c)}{(m+2)}+\frac{2(1-c)^{2}}{(m+2)(m+3)}\right]}\right\}^{1+\frac{1}{m}} \\
& \cdot \int_{a}^{b^{+}} \frac{r^{+}}{(1-c)}\left(\frac{r^{+}-c}{1-c}\right)^{m} r^{+} d r^{+} \\
= & \frac{\eta \bar{u}^{2} \pi \Delta x}{(m+1)(1-c)^{m+1}}
\end{aligned}
$$$$
\left\{\frac{m+1}{(1-c)\left[1-\frac{2(1-c)}{(m+2)}+\frac{2(1-c)^{2}}{(m+2)(m+3)}\right]}\right\}^{1+\frac{1}{m}}
$$$$
\cdot\left(\mathbf{r}^{+}-\mathbf{c}\right)^{\mathrm{m}+1}
$$$$
\cdot\left[\mathbf{r}^{+^{2}}-\frac{2 \mathbf{r}^{+}\left(\mathbf{r}^{+}-\mathrm{c}\right)}{\mathrm{m}+2}+\frac{2\left(\mathbf{r}^{+}-\mathrm{c}\right)^{2}}{(\mathbf{m}+2)(\mathbf{m}+3)}\right]\left[\begin{array}{l}
\mathbf{r}^{+}=\mathbf{b}^{+} \\
\mathbf{r}^{+}=\mathbf{a}^{+}
\end{array}\right.
$$

This result can be written more compactly as

$$
\mathbf{U}=\mathbf{H}\left[\psi\left(\mathbf{b}^{+}\right)-\psi\left(\mathbf{a}^{+}\right)\right]
$$

where

$$
\begin{aligned}
& H=\frac{\eta \bar{u}^{2} \pi \Delta x}{(m+1)(1-c)^{m+1}} \\
& -\left\{\frac{m+1}{(1-c)\left[1-\frac{2(1-c)}{m+2}+\frac{2(1-c)^{2}}{(m+2)(m+3)}\right]}\right\}^{1+\frac{1}{m}}
\end{aligned}
$$

and

$$
\begin{aligned}
& \psi\left(\mathrm{r}^{+}\right)=\left(\mathrm{r}^{+}-\mathrm{c}\right)^{\mathrm{m}+1} \\
& \cdot\left[\mathrm{r}^{+^{2}}-\frac{2 \mathrm{r}^{+}\left(\mathrm{r}^{+}-\mathrm{c}\right)}{\mathrm{m}+2}+\frac{2\left(\mathrm{r}^{+}-\mathrm{c}\right)}{(\mathrm{m}+2)(\mathrm{m}+3)}\right]
\end{aligned}
$$

The element viscous dissipation for each of the four cases can be written as follows:

Case 1

$$
\left[\begin{array}{l}
\mathrm{U}_{\mathrm{i}} \\
\mathrm{U}_{\mathrm{j}} \\
\mathrm{U}_{\mathrm{k}} \\
\mathrm{U}_{\ell}
\end{array}\right]^{(0)}=\mathbf{H}\left[\begin{array}{l}
\psi\left(\mathrm{r}_{\mathrm{e}}^{+}\right)-\psi\left(\mathrm{r}_{\mathrm{i}}^{+}\right) \\
\psi\left(\mathrm{r}_{\mathrm{e}}^{+}\right)-\psi\left(\mathrm{r}_{\mathrm{i}}^{+}\right) \\
\psi\left(\mathrm{r}_{\ell}^{+}\right)-\psi\left(\mathrm{r}_{\mathrm{e}}^{+}\right) \\
\psi\left(\mathrm{r}_{\ell}^{+}\right)-\psi\left(\mathrm{r}_{\mathrm{e}}^{+}\right)
\end{array}\right]
$$

\section{Case 2}

$$
\left[\begin{array}{l}
\mathrm{U}_{\mathrm{i}} \\
\mathrm{U}_{\mathrm{j}} \\
\mathrm{U}_{\mathrm{k}}^{(\bullet)} \\
\mathrm{U}_{\ell}
\end{array}\right]^{(0)}\left[\begin{array}{l}
\psi\left(\mathrm{r}_{\mathrm{e}}^{+}\right) \\
\psi\left(\mathrm{r}_{\bullet}^{+}\right) \\
\psi\left(\mathrm{r}_{\ell}^{+}\right)-\psi\left(\mathrm{r}_{\mathrm{e}}^{+}\right) \\
\psi\left(\mathrm{r}_{\ell}^{+}\right)-\psi\left(\mathrm{r}_{\mathrm{e}}^{+}\right)
\end{array}\right]
$$

Case 3

$$
\left[\begin{array}{c}
\mathrm{U}_{\mathrm{i}} \\
\mathrm{U}_{\mathrm{j}}^{\left({ }^{())}\right.} \\
\mathrm{U}_{\mathrm{k}} \\
\mathrm{U}_{\ell}
\end{array}\right]^{\mathrm{H}}\left[\begin{array}{c}
0 \\
0 \\
\psi\left(\mathrm{r}_{\ell}^{+}\right) \\
\psi\left(\mathrm{r}_{\ell}^{+}\right)
\end{array}\right]
$$

\section{Case 4}

$$
\left[\begin{array}{c}
\mathrm{U}_{\mathrm{i}} \\
\mathrm{U}_{\mathrm{j}} \\
\mathrm{U}_{\mathrm{k}}^{(0)} \\
\mathrm{U}_{t}
\end{array}\right]^{-}\left[\begin{array}{l}
0 \\
0 \\
0 \\
0
\end{array}\right]
$$

The element capacitance will be defined using a "lumped-capacitance" approach; the resulting element capacitance matrix is diagonal:

\section{Lumped Capacitance}

$\left[\begin{array}{l}\mathrm{C}_{\mathrm{i}} \\ \mathrm{C}_{\mathrm{j}} \\ \mathrm{C}_{\mathrm{k}} \\ \mathrm{C}_{\ell}\end{array}\right]^{(e)}=\frac{\left(\rho \mathrm{C}_{v}\right)}{4 \Delta \mathrm{t}}\left[\begin{array}{llll}1 & 0 & 0 & 0 \\ 0 & 1 & 0 & 0 \\ 0 & 0 & 1 & 0 \\ 0 & 0 & 0 & 1\end{array}\right]\left[\begin{array}{l}\mathrm{T}_{\mathrm{i}}^{\mathrm{n}+1}-\mathrm{T}_{\mathrm{i}}^{\mathrm{n}} \\ \mathrm{T}_{\mathrm{j}}^{\mathrm{n}+1}-\mathrm{T}_{\mathrm{j}}^{\mathrm{n}} \\ \mathrm{T}_{\mathrm{k}}^{\mathrm{n}+1}-\mathrm{T}_{\mathrm{k}}^{\mathrm{n}} \\ \mathrm{T}_{\ell}^{\mathrm{n}+1}-\mathrm{T}_{\ell}^{\mathrm{n}}\end{array}\right]$

(B-27) 
The boundary conditions will be specified now. Adiabatic boundary conditions naturally occur during the assembly of the element relationships into the global equations. Specified temperature boundaries are produced by replacing the energy balance equation for the desired node by

$a T_{i}^{n+1}=a \cdot T_{\text {specified }}$

where " $a$ " is a large number, say $10^{10}$; this procedure is standard in Finite-Element procedures.

The energy convected by fluid motion across the inflow boundary $\mathrm{i}-\ell$ in Figure B-2 can be written as

\section{Convective Inflow}

$\left[\begin{array}{l}E_{i} \\ E_{t}\end{array}\right]_{x}^{(\theta)}=\frac{1}{2}\left(A_{x} \rho c\right)^{(0)}\left[\begin{array}{cc}u_{S} & 0 \\ 0 & u_{N}\end{array}\right]^{(\theta)}\left[\begin{array}{l}T_{i} \\ T_{i}\end{array}\right]$

Similarly for the outflow boundary $\mathbf{j}-\mathbf{k}$,

Convective Outflow

$\left[\begin{array}{l}E_{j} \\ E_{k}\end{array}\right]_{x}^{(0)}=\frac{1}{2}\left(A_{x} \rho c\right)^{(0)}\left[\begin{array}{cc}u_{s} & 0 \\ 0 & u_{N}\end{array}\right]^{(e)}\left[\begin{array}{l}T_{j} \\ T_{k}\end{array}\right]$

For convective heat transfer across a solid/fluid interface, it will be assumed that each element has its own value of the convective heat-transfer coefficient $h^{(e)}$ and ambient fluid temperature $T_{\infty}^{(e)}$. If the $i-j$ boundary is losing heat by convection, then

\section{Solid/Fluid Convection}

$\left[\begin{array}{l}Q_{i} \\ Q_{j}\end{array}\right]_{h}^{(e)}=\pi r_{i} \Delta x h^{(e)}\left[\begin{array}{l}T_{i}-T_{\infty} \\ T_{j}-T_{\infty}\end{array}\right]^{(e)}$

(B-31)

Now that all of the element matrices have been defined, the usual element-assembly procedures can be used to assemble the governing algebraic equations. Figure B-5 represents all of the element energy and heat flow terms that contribute to the energy balance on a typical control volume (node 5). The complete energy balance can be written as

$$
\begin{aligned}
& E_{b_{z}}^{(4)}+Q_{\delta_{z}}^{(4)}+E_{\delta_{z}}^{(3)}+Q_{b_{z}}^{(3)}-\left(E_{\delta_{z}}^{(2)}+Q_{b_{z}}^{(2)}+E_{\delta_{z}}^{(1)}+Q_{\delta_{z}}^{(1)}\right) \\
& +Q_{5_{r}}^{(1)}+Q_{5_{r}}^{(2)}+Q_{5_{r}}^{(3)}+Q_{5_{r}}^{(1)}+C_{5}^{(1)}+C_{5}^{(2)}+C_{5}^{(3)}+C_{5}^{(4)} \\
& =\mathrm{U}_{5}^{(1)}+\mathrm{U}_{5}^{(2)}+\mathrm{U}_{5}^{(3)}+\mathrm{U}_{5}^{(4)}
\end{aligned}
$$

3

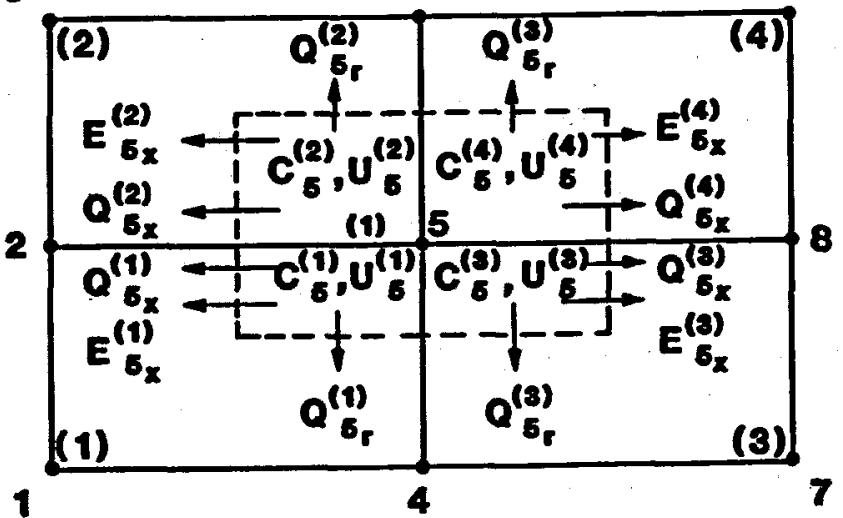

Flgure B-5. Element Energy Flow, Heat Flow, Capacitance, and Source Terms that Contribute to the Energy Balance on Node 5

The heat and energy flow terms were all evaluated at time $n+1$; this results in a fully implicit time integration, and the resulting linear algebraic equations are directly solved using the band-solver routine SNBFS available on the SLATEC Library. ${ }^{3}$

\section{References}

${ }^{2}$ D. B. Spalding, "A Novel Finite-Difference Formulation for Differential Expressions Involving Both First and Second Derivatives," Int. J. Numerical Method in Engineering, Vol 4, 551-559 (1972).

2S. V. Patankar, Numerical Heat Transfer (Washington, DC: Hemisphere, 1980).

${ }^{3}$ K. H. Haskell, W. H. Vandevender, and E. L. Walton, The SLATEC Common Mathematical Subprogram Library: SNLA Implementation, SAND80-2792 (Albuquerque, NM: Sandia National Laboratories, December 1980). 



\section{APPENDIX C}

\section{Description of Temperature-Profile Probe}

The probe used for measuring a temperature profile was formed by butt welding $0.076-\mathrm{mm}(0.003-\mathrm{in}$.) diameter chromel/alumel thermocouple (Type K) wire and flattening the weld to $0.127 \mathrm{~mm}(0.005 \mathrm{in}$.). An ice bath is used for the reference junction.

The wires are taken out through a $0.81-\mathrm{mm}$ (0.032-in.) OD by $13-\mathrm{mm}(0.50$-in.) long hypodermic needle that is attached to a $1.6-\mathrm{mm}(1 / 16-\mathrm{in}$.) OD brass tube. Small holes were drilled into the needle and the brass tube, the needle was inserted into the tube at a slightly obtuse angle, and the two were joined with solder. The junction extends approximately $2.92 \mathrm{~mm}(0.115 \mathrm{in}$.) beyond the end of the needle and is flush with the outer wall of the needle on the opposite side from the brass tube. The junction is located 15.5-mm (0.609-in.) upstream of the brass tube centerline. An epoxy coating on the exposed wires provides rigidity and electrical insulation; the junction is not coated. Due to the OD of the hypodermic needle and the slight obtuse angle, the probe can only reach $1.88 \mathrm{~mm}(0.074 \mathrm{in}$.) from the near wall; it can, however, touch the opposite pipe wall. Figure C-1 is a photograph of the probe.
The probe is positioned with a micrometeradjusted transversing device. From the exit of the heated section, the foam passes through a nylon bushing and into a chlorinated polyvinyl chloride (CPVC) adapter. The inner diameter of the adapter is 25.83 $\mathrm{mm}$ (1.017 in.) and is within $.05 \mathrm{~mm}(0.002 \mathrm{in}$.) of the test section diameter. A cross-section of the transversing mechanism is shown in Figure C-2. This figure was adapted from the fabrication prints and actual dimensions vary slightly. $A C P V C$ plug, which is threaded on both ends, attaches the transversing mechanism to the adapter. One end of the plug has the same radius of curvature as the adapter and forms a smooth joint with the adapter so that there is little disturbance of the flow. The exterior surface of the adapter is machined flat in one location so that the plug fits flush against the adapter. The plug/adapter connection is sealed with an 0 -ring. The $1.6-\mathrm{mm}(1 / 16$-in.) shank of the probe fits into a hole in the plug, and this connection is also sealed with an 0 -ring. 


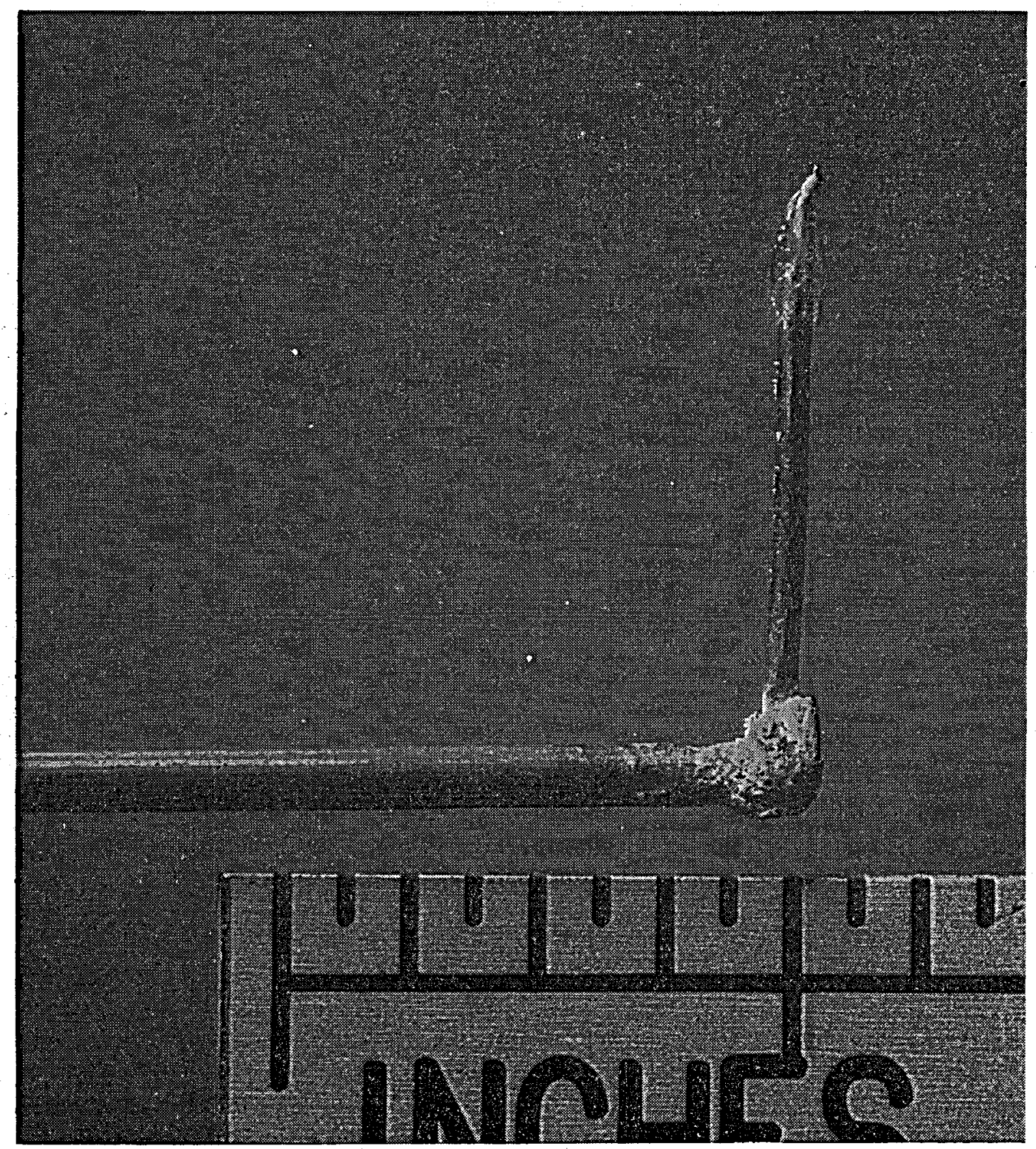

Figure C-1. Microphotograph of Temperature Measurement Probe (each small division is $1 / 16 \mathrm{in}$.) 


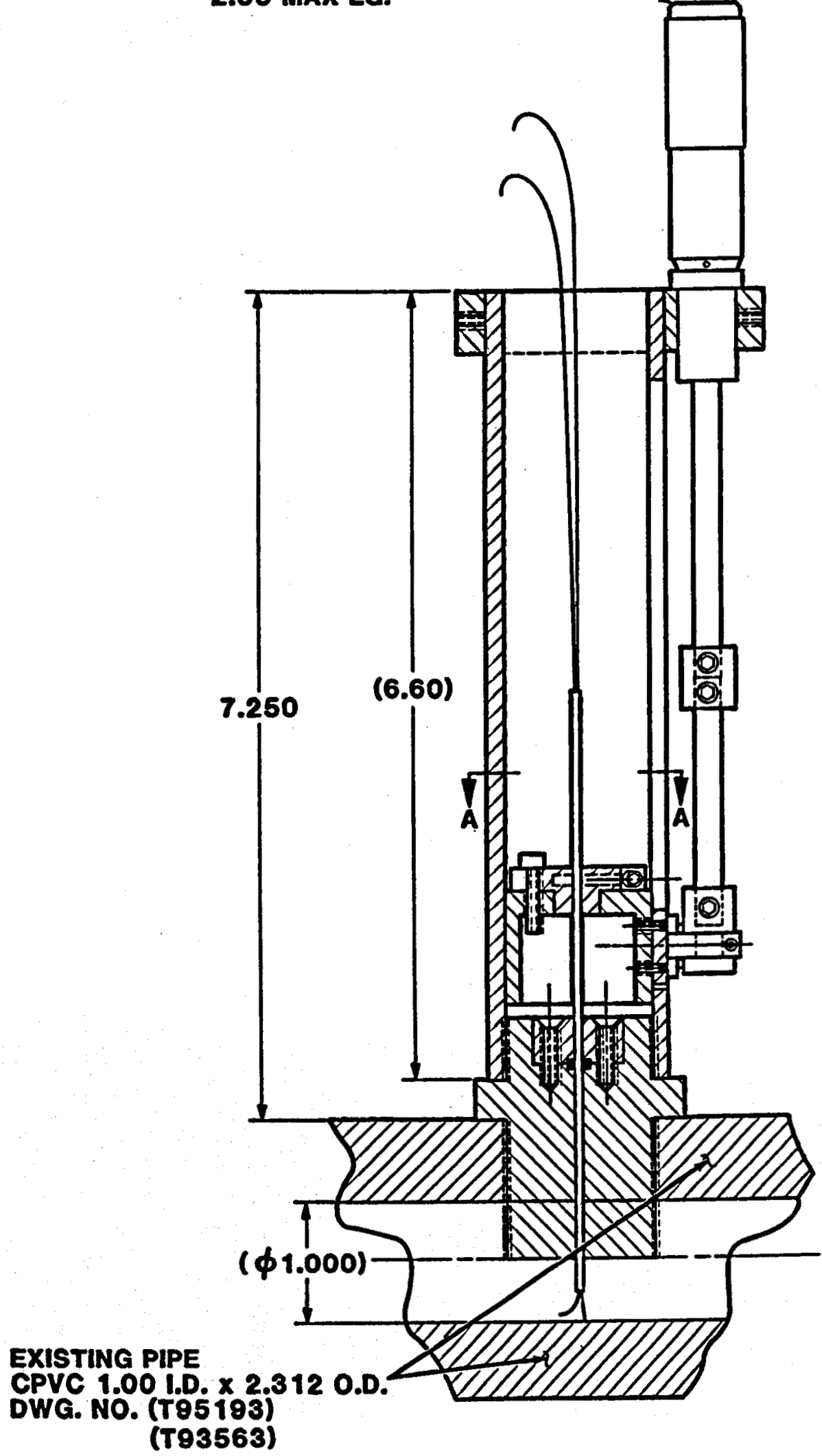

Figure C-2. Schematic of Temperature/Velocity Probe Traversing Mechanism (all dimensions are in inches) 



\section{APPENDIX D}

\section{Calibration of Hot-Film Anemometer}

The recommended form of the calibration equation for a hot film probe in air or water is given by Reference 1:

$$
E^{2}=\left[A+B(\rho u)^{1 / n}\right]\left(T_{s}-T_{e}\right)
$$

where,

$$
\begin{array}{ll}
\rho & =\text { density, } \\
\mathbf{u} & =\text { local velocity, } \\
\mathrm{T}_{\mathrm{e}} & =\text { environment (local-fluid) temperature, } \\
\mathrm{T}_{\mathrm{s}} & \text { = sensor operating temperature (fixed by } \\
\mathrm{E} & \text { bridge resistance), } \\
\mathrm{E} & \text { anemometer output voltage, and }
\end{array}
$$$$
(A, B, n)=\text { calibration constants to be determined. }
$$

Although this calibration equation has not been verified for a non-Newtonian fluid like aqueous foam, it was deemed a valid starting point. Equation (D-1) can be solved for the density/velocity product to give

$$
\rho u=\left\{\frac{1}{B}\left[\frac{E^{2}}{\left(T_{s}-T_{0}\right)}-A\right]\right\}^{n} .
$$

The integral of the density-velocity product over the cross-section of the test section results in the mass flow rate:

$$
\begin{aligned}
& \dot{m}=2 \pi \int_{0}^{r_{w}} \rho \text { urdr }= \\
& 2 \pi \int_{0}^{r_{w}}\left\{\frac{1}{B}\left[\frac{E^{2}}{\left(T_{0}-T_{0}\right)}-A\right]\right\}^{n} r d r .
\end{aligned}
$$

The above integration was performed numerically using the trapezoidal rule and experimental voltage data from the test-section centerline to the "far" wall. No slip at the wall was assumed. Construction of the probe did not allow measurements to be taken closer than $0.318 \mathrm{~mm}(0.0125 \mathrm{in}$.) to the wall.

The mass flow rate is measured experimentally by individually metering the gas and liquid components. A nonlinear parameter estimation program (NLINA) ${ }^{2}$ is used to estimate the calibration constants. NLINA determines values for the constants that produce a minimum sum of the squares of the differences between the measured mass flow rate and the corresponding calculated value. NLINA uses the partial derivatives of the mass flow rate with respect to each of the calibration constants (sensitivity coefficients) to determine the next estimate for the constants.

Using computer-generated data, NLINA would converge for the three parameters $(A, B, n)$; however, convergence problems were experienced when experimental data (which contained errors) were used. To avoid this problem the exponent, $n$, was specified and the other two constants $(A, B)$ were estimated. This process was repeated for various values of the exponent ranging between three and seven. The preferred value of the exponent could be determined by that value which produced the best fit of the calculated to the measured mass flow rates. The fit, however, was determined to be relatively insensitive to the value of the exponent. The anemometer operating manual indicates that the exponent is approximately two for "normal" fluids; the value of, $n$, nearest to two that resulted in convergence was chosen as the preferred value.

The resulting calibration constants used are

$\mathrm{A}=27.33, \quad \mathrm{~B}=0.2155, \quad \mathrm{n}=3.0$.

These constants were determined for velocity in $\mathrm{ft} / \mathrm{s}$, density in $\mathrm{lb}_{\mathrm{m}} / \mathrm{ft}^{3}$, temperature difference in ${ }^{\circ} \mathrm{F}$, anemometer output in $\mathrm{V}$, radial position in $\mathrm{ft}$, and mass flow rate in $\mathrm{lb}_{\mathrm{m}} / \mathrm{s}$.

The calibration constants are likely to be dependent upon the structure of the foam. If the foam structure varies with such variables as liquid volume fraction, pressure, and pressure gradient, a single set of calibration constants would not be valid for different flow conditions, and might not even be valid for all radial positions within a single flow.

Figure D-1 presents the calculated mass flow rate as a function of the experimental mass flow rate; only four experimental velocity profiles were used. Due to the scatter in the mass flow rate data and the small number of experimental velocity profiles, the validity of Equation (D-1) for aqueous foams was not rigorously established. 


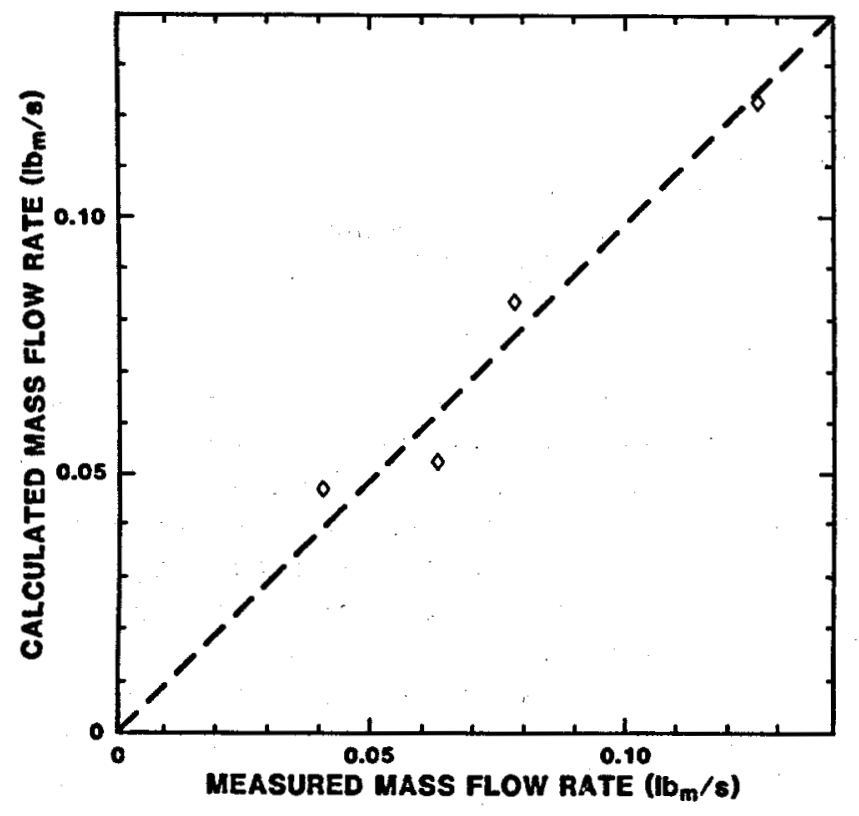

Figure D-1. Comparison Between Calculated and Measured Mass Flow Rates

\section{References}

${ }^{14}$ Hot Film and Hot Wire Anemometry, Theory and Application," Technical Bulletin TB 5 (St. Paul, MN: TSI).

2J. V. Beck, Michigan State University. Private Communication. 


\section{DISTRIBUTION:}

DOE/TIC-4500, R74, UC-66d (223)

Los Alamos National Laboratory

Attn: J. C. Rowley, MS-570

PO Box 1663

Los Alamos, NM 87545

Texas A\&M University

Dept. of Geosciences

Attn: M. Friedman, Dean

College Station, TX 77843

US Department of Energy

Office of Basic Energy Sciences

Attn: G. A. Kolstad

GPN Bldg. G-226

Washington, DC 20585

Shell Oil Company

Two Shell Plaza

Attn: E. Bingman

PO Box 2099

Houston, TX 77001

Mobil Research \& Development Corporation

Dallas Research Laboratory

Attn: E. Martin

13777 Midway Rd.

Dallas, TX 75224

Amoco Production Company

Research Center

Attn: T. Warren

PO Box 591

Tulsa, OK 74102

Stratabit

Attn: L. Matson

600 Kenrick, Suite A1

Houston, TX 77060

Dresser Industries Security Division

Attn: J. Langford

PO Box 2467

Dallas, TX 75224

Union Oil Co. of California

Union Geothermal Division

Union Oil Center

Attn: S. Pye

$461 \mathrm{~S}$. Boylston

Los Angeles, CA 90017
US Department of Energy (3)

Geothermal Technologies Division

Forrestal Bldg., CE-324

Attn: R. Toms

J. Bresee

M. J. Reed

1000 Independence Ave., SW

Washington, DC 20585

Geothermal Resources International Inc.

Attn: J. Combs

1825 S. Grant, Suite 900

San Mateo, CA 94402

Livesay Consultants

Attn: B. J. Livesay

2616 Angell Ave.

San Diego, CA 92122

US Department of Energy

Albuquerque Operations Office

Attn: G. P. Tennyson

PO Box 5400

Albuquerque, NM 87115

Geothermal Energy Research \&

Development Co., LTD.

Attn: Chuji Araki

Kyodo Bldg.

11-7, Kabuto-Cho, Nihonbashi

Chuo-Ku, Tokyo. 103, JAPAN

James Burns

32 Mahler Ct.

Appleton, WI 54915

University of Arkansas

Mechanical Engineering Department

Attn: H. Wolf

Fayetteville, AR 72701

1000

V. Narayanamurti

1510 J. W. Nunziato

1511 A. M. Kraynik (10)

1511 L. A. Mondy

1520 C. W. Peterson

1530 L. W. Davison

1550 R. C. Maydew

1551 J. K. Cole

1552 D. D. McBride 
DISTRIBUTION (continued):

\begin{tabular}{ll}
1553 & S. McAlees, Jr \\
1553 & B. F. Blackwell (20) \\
1554 & D. P. Aeschliman \\
1555 & W. R. Barton \\
1556 & W. L. Oberkampf \\
1813 & P. B. Rand \\
5214 & M. E. Larsen \\
6200 & V. L. Dugan \\
6231 & C. R. Carrigan \\
6241 & L. E. Duda, Jr (20) \\
6242 & J. C. Dunn \\
6242 & A. Ortega \\
6300 & R. W. Lynch \\
6330 & W. D. Weart \\
7521 & S. T. Letourneau \\
$\mathbf{7 5 3 0}$ & T. L. Workman \\
$\mathbf{7 5 3 1}$ & D. R. Schafer \\
$\mathbf{7 5 3 3}$ & F. H. Mathews \\
$\mathbf{7 5 3 5}$ & D. C. Bickel \\
7537 & N. R. Keltner \\
$\mathbf{7 5 3 7}$ & K. B. Sobolik (10) \\
$\mathbf{8 2 4 0}$ & C. W. Robinson \\
$\mathbf{8 5 2 4}$ & P. W. Dean \\
3141 & S. A. Landenberger (5) \\
$\mathbf{3 1 5 1}$ & W. L. Garner (3) \\
\hline &
\end{tabular}

